\title{
Cell cycle arrest through indirect transcriptional repression by p53: I have a DREAM
}

\author{
Kurt Engeland ${ }^{1}$
}

Activation of the p53 tumor suppressor can lead to cell cycle arrest. The key mechanism of p53-mediated arrest is transcriptional downregulation of many cell cycle genes. In recent years it has become evident that p53-dependent repression is controlled by the p53-p21-DREAM-E2F/CHR pathway (p53-DREAM pathway). DREAM is a transcriptional repressor that binds to E2F or CHR promoter sites. Gene regulation and deregulation by DREAM shares many mechanistic characteristics with the retinoblastoma pRB tumor suppressor that acts through E2F elements. However, because of its binding to E2F and CHR elements, DREAM regulates a larger set of target genes leading to regulatory functions distinct from PRB/E2F. The p53-DREAM pathway controls more than 250 mostly cell cycle-associated genes. The functional spectrum of these pathway targets spans from the $G_{1}$ phase to the end of mitosis. Consequently, through downregulating the expression of gene products which are essential for progression through the cell cycle, the p53-DREAM pathway participates in the control of all checkpoints from DNA synthesis to cytokinesis including $G_{1} / S, G_{2} / M$ and spindle assembly checkpoints. Therefore, defects in the p53-DREAM pathway contribute to a general loss of checkpoint control. Furthermore, deregulation of DREAM target genes promotes chromosomal instability and aneuploidy of cancer cells. Also, DREAM regulation is abrogated by the human papilloma virus HPV E7 protein linking the p53-DREAM pathway to carcinogenesis by HPV. Another feature of the pathway is that it downregulates many genes involved in DNA repair and telomere maintenance as well as Fanconi anemia. Importantly, when DREAM function is lost, CDK inhibitor drugs employed in cancer treatment such as Palbociclib, Abemaciclib and Ribociclib can compensate for defects in early steps in the pathway upstream from cyclin/CDK complexes. In summary, the p53-p21DREAM-E2F/CHR pathway controls a plethora of cell cycle genes, can contribute to cell cycle arrest and is a target for cancer therapy. Cell Death and Differentiation (2018) 25, 114-132; doi:10.1038/cdd.2017.172; published online 10 November 2017
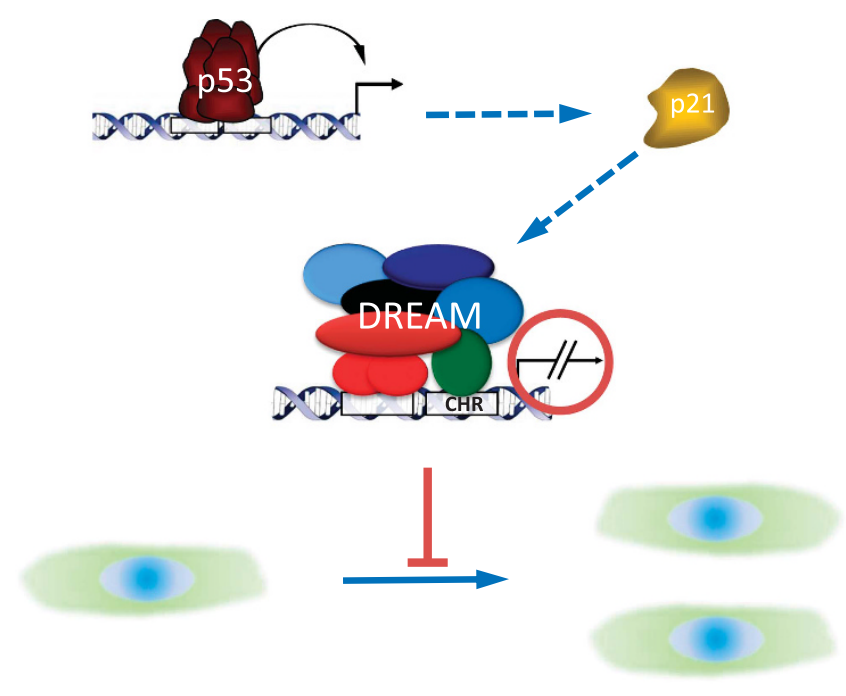

Graphical Abstract

Facts

- p53 causes cell cycle arrest

- p21/CDKN1A is required for indirect transcriptional repression by $\mathrm{p} 53$
- The DREAM protein complex is a transcriptional repressor

- CHR and E2F promoter elements bind the DREAM complex

- p21/CDKN1A initiates a switch from activating B-MYB- and FOXM1-containing complexes to the repressing DREAM complex

- p53 indirectly downregulates many cell cycle genes

Open Questions

- How do p63, p73 and p53 variants influence the p21DREAM-E2F/CHR (p53-DREAM) pathway?

- Are cellular kinase inhibitors other than p21/CDKN1A regulating this pathway?

- Which clinical benefits can be achieved in cancer treatment with small-molecule CDK inhibitors by compensating for defects in the p53-DREAM pathway?

- What are the overlaps or differences in pRB and DREAM function?

\section{Prologue}

One central role of the tumor suppressor p53 is to arrest the cell cycle. p53 indirectly downregulates the expression of many genes which are essential for progression through the cell division cycle. The detailed mechanism of indirect transcriptional repression by $\mathrm{p} 53$ has only recently become 
clear. p53 employs a protein complex named DREAM to downregulate gene expression. DREAM functions as a transcriptional repressor complex. With the advent of genome-wide experimental and bioinformatic analyses, we are now in the position to assess the wide spectrum of genes controlled through the newly defined p53-DREAM pathway.

\section{p53 Downregulates Expression of Cell Cycle Genes}

p53 is at the heart of several fundamental cellular signaling pathways. $^{1-4}$ The most important of these pathways for p53's tumor-suppressive role are induction of apoptosis and cell cycle arrest. ${ }^{5,6}$

Cell cycle arrest can be achieved by depleting regulatory proteins required for cell cycle progression. Upon p53 activation, genes for many central cell cycle proteins are transcriptionally downregulated. Key examples for genes repressed after induction of p53 are cyclin $A,{ }^{7}$ polo-like kinase 1 (PLK1), ${ }^{7}$ cyclin B1, ${ }^{8-10}$ cyclin B2, ${ }^{10}$ cyclin-dependent kinase 1 (CDK1), ${ }^{11} C D C 20,{ }^{12}$ cell cycle phosphatases $C D C 25 A^{13}$ and $C D C 25 C{ }^{14}$ DNA replication licensing factor $M C M 5,{ }^{7,15}$ $C K S 1^{16}$ and antiapoptotic Survivin (BIRC5). ${ }^{7}$ Even such a small selection of genes exemplifies that p53-dependent downregulation of expression affects many aspects of cell cycle regulation.

\section{Transcriptional Repression by p53 is Indirect}

Transcriptional regulation is essential to the function of p53 as a tumor suppressor. ${ }^{2}$ Interestingly, the number of genes downregulated after p53 activation (approximately 2700) is larger than the number of genes activated by p53 (approximately 2200). ${ }^{17}$ Before this enigma was finally solved, several mechanisms had been proposed to explain how p53 can serve as a transcriptional activator as well as a repressor. ${ }^{2,4,18}$ However, experimental data obtained for particular genes were often not consistent with the suggested mechanism or results published for certain genes by different groups were contradictory. ${ }^{17-19}$ Furthermore, different models for p53dependent repression require direct binding of p53 to the downregulated gene. However, genome-wide mRNA expression and chromatin immunoprecipitation (ChIP) results demonstrated that this requirement is not fulfilled for most repressed genes. Only about 3\% of the genes downregulated by $\mathrm{p} 53$ are also bound by p53. ${ }^{17}$ Thus, essentially all genes are downregulated by $\mathrm{p53}$ indirectly.

Prior to the availability of genome-wide ChIP data on binding of p53 and other factors potentially involved in transcriptional repression, it was not evident by which mechanism p53 downregulates a plethora of cell cycle genes. This changed when the mammalian DREAM complex together with its target genes was discovered ${ }^{20,21}$ and the observation was made that DREAM is formed following p53 induction. ${ }^{22}$

\section{DREAM is a Transcriptional Repressor}

The DREAM transcriptional complex displays two remarkable features. It changes its composition to exert opposing functions in gene regulation and it contains two subunits that bind to distinct DNA elements.
DREAM is composed of the MuvB core complex, E2F4-5/ $\mathrm{DP}$, and p130 or p107 proteins, which are related to the retinoblastoma tumor suppressor $\mathrm{pRB}^{20,21}$ (Figure 1). E2F4, E2F5 and p130/p107 had long been implicated in transcriptional repression via E2F sites. ${ }^{23}$ Consistently, DREAM was initially identified as a complex which binds promoters through E2F sites. ${ }^{20,21,24}$ However, DREAM loses its E2F/pRB-related components to associate with the transcriptional activators B-MYB and FOXM1 during the cell cycle. ${ }^{20,22,25-27}$ Thus, these MuvB-based complexes cannot bind E2F sites. DREAM as all other MuvB-derived complexes binds DNA through cell cycle genes homology regions (CHRs). ${ }^{28-30} \mathrm{CHR}$ transcriptional elements are distinct from E2F sites and are bound by the LIN54 component of MuvB ${ }^{31,32}$ (Figure 1).

MuvB-based complexes can switch their function. Association of MuvB with B-MYB or FOXM1 switches DREAM to B-MYB-MuvB (MMB), FOXM1-MMB or FOXM1-MuvB complexes and turns the MuvB core from repressor to activator. This change in protein composition of MuvB-based complexes is connected to progression through the cell cycle and explains the switch from repression to activation via the same DNA site in the target promoters, that is, the CHR element (Figure 1).

It has been discussed whether B-MYB and FOXM1 require additional direct DNA binding when they are in a complex with MuvB. ${ }^{19,26,29,31,33-37}$ Generally, MYB consensus sites or forkhead binding sites are not observed close to the MuvBbinding $\mathrm{CHR}$ elements. For FOXM1 it was reported that it mostly binds to non-forkhead binding sites in the genome and that this nonspecific DNA binding may support association of MuvB with DNA. ${ }^{35,36}$ Possibly, also B-MYB binds to sites far from CHR elements to augment MMB-LIN54 binding to DNA.

Recently, the importance of $\mathrm{CHR}$ sites in cancer signaling pathways yet again has been demonstrated when the computer software SWltchMiner (SWIM) was employed to search for crucial nodes in signaling networks - called switch genes - out of a large panel of cancer data sets from The Cancer Genome Atlas. ${ }^{38}$ The analysis yielded 100 significant switch genes which are mostly upregulated in a panel of different tumor types. With this selection of genes a de novo motif search for promoter elements was carried out. Interestingly, the $\mathrm{CHR}$ element emerged as a crucial site central to the regulation of the switch genes from the cancer signaling nodes. $^{38}$

In addition to binding to single E2F or CHR sites, DREAM binding can be supported by two other elements, CDE (cell cycle-dependent element) and CLE (CHR-like element) sites (Figure 2). CLE sites are weak CHR-like elements and augment binding of DREAM to E2F sites. In general, affinity of CLE sites toward MuvB-based complexes, also the activating complexes, is not sufficient for binding. CLE sites alone cannot bind DREAM and an E2F element is required in tandem. Also, promoters require a spacer of four nucleotides between E2F and CLE sites. ${ }^{33}$ Similarly, CDE sites support binding of DREAM only when a CHR element is present in the promoter. Again, a spacer of four bases is found between CDE and CHR sites. ${ }^{33}$ CHR and CLE sites are contacted by LIN54 of the MuvB core complex. ${ }^{28,32}$ Thus, DREAM binds to promoter DNA by four different modes ${ }^{33}$ (Figure 2). 
Cell cycle and transcription factor complexes
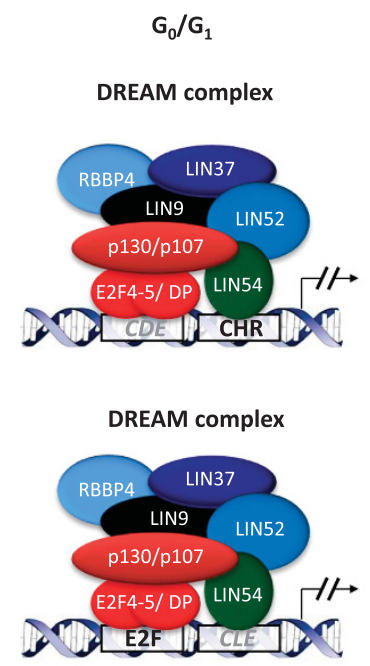

late $\mathrm{G}_{1}$ /early $\mathrm{S}$

MMB

B-MYB-MuvB complex

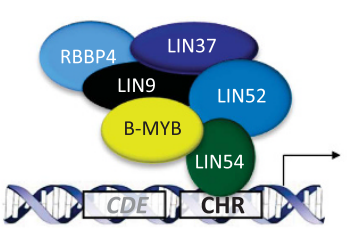

late S/early $\mathrm{G}_{2}$

FOXM1-MMB complex

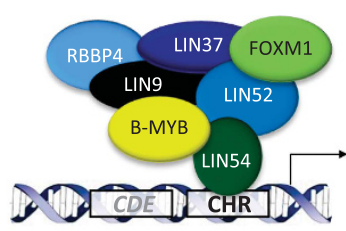

$G_{2} / M$
FOXM1-MuvB complex

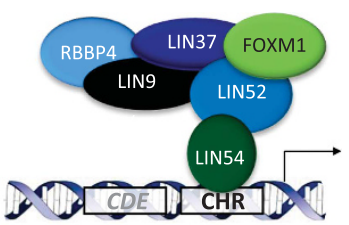

heterodimeric complex

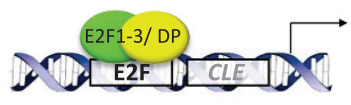

repression

1

activation

Figure 1 Cell cycle and transcription factor complexes. The protein complexes binding to DNA change during the cell cycle. Gene expression is repressed in the early phases of the cell cycle and becomes activated during the later phases. For this change, E2F and $\mathrm{CHR}$ (cell cycle genes homology region) promoter elements switch from repressor to activator sites. In $G_{0}$ and early $G_{1}$ phase the DREAM complex binds E2F, CHR, CDE (cell cycle-dependent element), and CLE (CHR-like element) sites to repress transcription. In $\mathrm{G}_{2}$ phase and mitosis transcriptional repression is released and activation occurs via CHR sites. Only promoters with CHR sites can bind the MuvB-based complexes MMB (BMYB-MuvB), FOXM1-MMB and FOXM1-MuvB. The MuvB core complex is composed of LIN9, LIN37, LIN52, LIN54 and RBBP4 proteins. LIN54 is the component which binds to CHR elements. For the switch from repressing to activating complexes, B-MYB and FOXM1 are recruited to the MuvB core when E2F4-5/DP and p107/p130 dissociate from the complex. B-MYB-MuvB (MMB), FOXM1-MMB and FOXM1-MuvB complexes serve as activators of late cell cycle genes which carry functional CHR elements. Early cell cycle genes with maximum expression in the $\mathrm{S}$ phase are activated by E2F1-3/DP heterodimers through E2F sites

\section{Modes of DREAM binding}

a

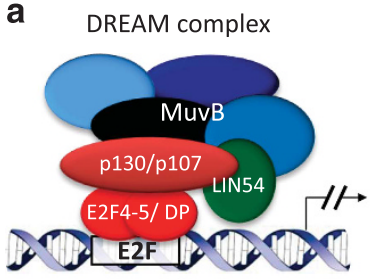

C

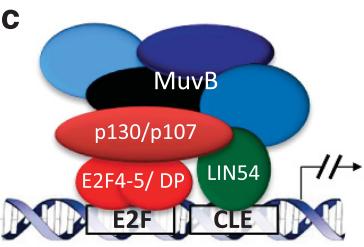

E2F supported by CLE site

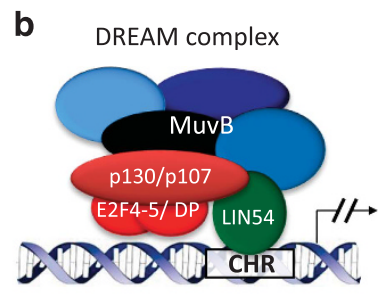

d

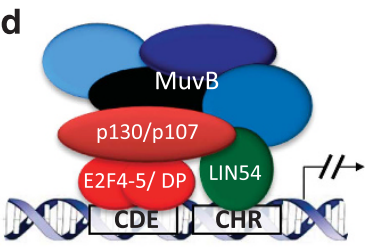

CHR supported by CDE site
Figure 2 Modes of DREAM binding. DREAM can form two distinct contacts with DNA. It can bind to DNA via single E2F (a) or CHR (b) sites. E2F sites are contacted through E2F4-5/DP heterodimers. Distinct from this binding, contacts to CHR elements are made via the LIN54 protein. In the figure, the LIN54 component of the MuvB core complex is the only constituent that is labeled. Binding to $\mathrm{E} 2 \mathrm{~F}$ or $\mathrm{CHR}$ elements can be supported by CLE (c) or CDE (d) sites, respectively. CDE and CLE sites differ from E2F and CHR elements as CDE and CLE sites are unable to bind DREAM as single elements

\section{The p53-p21-DREAM-E2F/CHR Pathway}

After the discovery of DREAM binding to E2F and $\mathrm{CHR}$ elements, the pathway by which p53 downregulates many genes became evident. ${ }^{39}$ In short, this pathway requires transcriptional upregulation of p21/CDKN1A. p21/CDKN1A inhibits cyclin-dependent kinases (CDKs) which phosphorylate the pRB-related proteins p107 and p130. Thus, p21/ CDKN1A expression results in hypophosphorylation of $p 107$ and p130. In this hypophosphorylated state, p107 and p130 can join other proteins to form the DREAM complex and thereby repress transcription through DREAM binding to E2F or CHR promoter sites (Figure 3).

The CDK inhibitor p21/CDKN1A (WAF1, CIP1) was the first transcriptional target identified for $\mathrm{p} 53 .{ }^{40,41}$ And with this target the more detailed description of the pathway starts. Upon p53 activation, $p 21 / C D K N 1 A$ is transcriptionally upregulated through direct binding of p53 to sites in the p21/CDKN1A promoter (Figure 3). ${ }^{39}$

One question that still needs to be addressed systemically is how the p53-related $p 63$ and p73 protein families influence transcription of $p 21 / C D K N 1 A$. Especially the TAp63/TAp73 variants have similar functions in regulating gene transcription as p53. ${ }^{42,43}$ The DNA binding motifs for p63, p73 and p53 are apparently essentially identical, ${ }^{44-47}$ suggesting that the transcriptionally active members of the p63 and p73 families may contribute to cell cycle arrest through activating p21/ CDKN1A. ${ }^{43,48,49}$ However, early experiments with overexpression of p63 and p73 variants indicated a reduced ability to induce $p 21 / C D K N 1 A$ expression compared with p53 and showed only minor effects on genes which are downregulated by $p 53 .^{13,16,48,50,51}$ 
The p53-p21-DREAM-E2F/CHR pathway

Indirect p53-dependent repression through DREAM

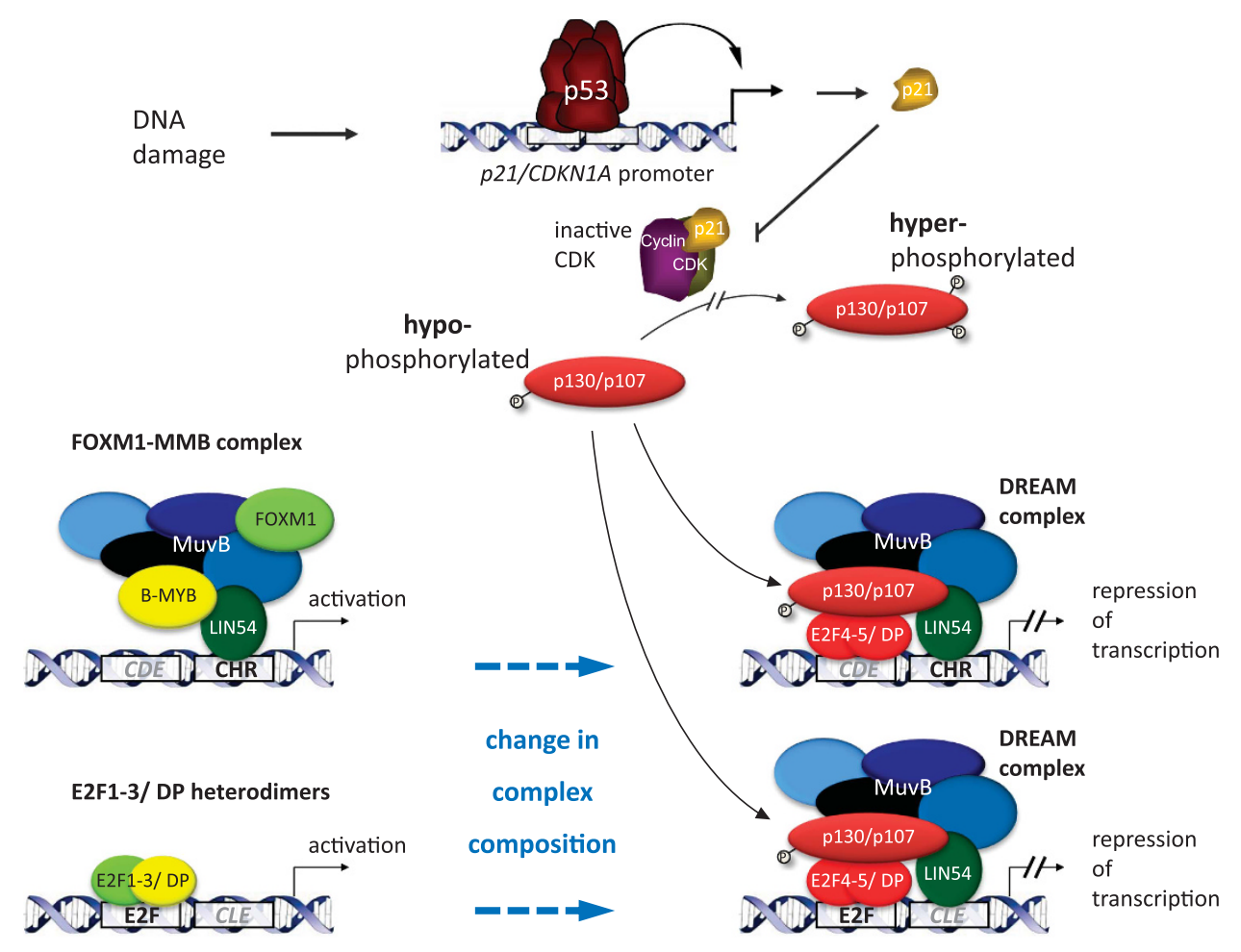

Figure 3 The p53-p21-DREAM-E2F/CHR pathway. Indirect p53-dependent repression through DREAM. Induction of p53 leads to downregulation of genes. This regulation is indirect as p53 does not bind to the regulated genes. Instead, induction of p21/CDKN1A expression by p53 causes hypophosphorylation of p107 and p130. Hypophosphorylation of these pRB-related pocket proteins facilitates DREAM formation. DREAM complexes then displace the activating complexes FOXM1-B-MYB-MuvB (FOXM1-MMB) and E2F1-3/DP on the target promoters. (In the figure, LIN54 is the only labeled MuvB component.) Overall, this switch causes previously activated genes to be indirectly downregulation by p53

Another challenge in delineating activation of $p 21 / C D K N 1 A$ is the formation of hetero-tetramers between $\mathrm{p} 53$ isoforms and the various proteins of the p53/p63/p73 family. ${ }^{52,53}$ In particular, tetramer formation including isoforms such as $\triangle 40 p 53$ and $\Delta 133 p 53$ may compromise activation of $p 21 /$ CDKN1A by other p53 family members. ${ }^{43}$ Which combination of p53 isoforms and other p53/p63/p73 family members compete for binding sites in the $p 21 / C D K N 1 A$ promoter depends on cell type and developmental stage-specific expression of these factors.

As the next step in the p53-DREAM pathway, p21/CDKN1A inhibits cyclin-dependent kinase complexes such as cyclin E/ A-CDK2 and cyclin D-CDK4/6. ${ }^{54,55}$ In turn, these cyclin/CDK complexes are no longer able to phosphorylate p107 and p130. ${ }^{56}$ The resulting hypophosphorylated p107 or p130 proteins attach to the MuvB core complex and shift the equilibrium from FOXM1-MMB to DREAM. ${ }^{22,35,39}$ Concomitant to this shift in MuvB-derived complex composition, transcriptional activation through FOXM1-MMB switches to repression by DREAM. Thus, genes active before p53 activation become repressed following p53 induction (Figure 3). At this step, the DREAM pathway shows a parallel regulation to the control by $\mathrm{pRB}$ because hypophosphorylation of $\mathrm{pRB}$ leads to $\mathrm{pRB} / \mathrm{E} 2 \mathrm{~F}$ complex formation. ${ }^{57}$
p21/CDKN1A is most likely not the only protein which can inhibit cyclin/CDK complexes that can phosphorylate p107 and $\mathrm{p} 130$, thereby promoting DREAM formation. ${ }^{56}$ Other CDK inhibitor proteins can substitute for p21/CDKN1A to inhibit cyclin E/A-CDK2 and cyclin D-CDK4/6 combinations.

These inhibitors include p27/Kip1/CDKN1B and p57/Kip2/ CDKN1C, both members of the Cip/Kip family with broad complex formation capacity, as well as p16/INK4A/CDKN2A, p15/INK4B/CDKN2B, p18/INK4C/CDKN2C and p19/INK4D/ CDKN2D of the INK4 family with narrow binding specificity towards cyclin D-CDK4/6 complexes. ${ }^{58}$

Although the function of p21/CDKN1A in cell cycle checkpoint control and thus a possible role in tumor suppression has been confirmed many times, one observation that may be related to this possible cdk inhibitor redundancy is the absence of p21/CDKN1A mutations in tumors and the lack of spontaneous tumorigenesis in p21/Cdkn1a $(-/-)$ mice. ${ }^{59,60}$ Consistently, recent results from several knockout models show that loss of p21/CDKN1A function alone is not sufficient for tumor development. ${ }^{61,62}$

Cyclin-dependent kinase regulation may even be more complex. Contrasting the canonical CDK inhibitor function, potential activation of cyclin/CDK complexes by p21/CDKN1A and $\mathrm{p} 27 / \mathrm{Kip} 1 / \mathrm{CDKN1B}$ has been discussed, with CDK 
inhibitors functioning as cyclin/CDK assembly factors, mediating nuclear localization of D-type cyclins, and contributing to stability of cyclin D-CDK4 complexes. ${ }^{58,63,64}$ Thus, it remains open whether additional signaling steps aside from the p53p21/CDKN1A axis signal into the DREAM pathway.

Target gene selection by DREAM dictates the cellular response of indirect p53-mediated gene repression. Four types of binding represented by the two main classes of target genes with either E2F or CHR sites can be distinguished (Figure 2). Depending on the specific promoter of the gene, either E2F or CHR elements bind the complexes independently or with the support of CDE or CLE sites, respectively (Figures 2 and 3).

Before the p53-dependent switch to transcriptional repression, target genes are activated by two different mechanisms. E2F elements bind E2F1-3/DP proteins for activation, whereas promoters carrying $\mathrm{CHR}$ sites are activated by FOXM1-MMB. Both groups of promoter elements then switch to DREAM binding for repression (Figure 3).

Taken together, this sequence of reactions constitutes the p53-p21-DREAM-E2F/CHR or short the p53-DREAM pathway. $^{39}$

\section{Target Genes for Indirect p53-Dependent Repression}

With the p53-DREAM pathway as a basis, criteria for identification of targets for indirect transcriptional downregulation by p53 are straightforward to define. Downregulation of target mRNA following p53 activation, DREAM binding to the target gene, and the presence of E2F or CHR sites in the proximal promoter are pivotal criteria for identification of target genes. There are many studies describing changes in mRNA levels employing a few different cell systems to compare expression with or without active p53. ${ }^{17,65}$ Furthermore, the binding of DREAM components to these target genes can be assayed by ChIP. Subsequently, this information can be combined with the presence of E2F or CHR sites in the promoters. Of course, the quality of p53-DREAM target identification improves considerably the more results from independent studies are combined. We have employed bioinformatic tools to search for overlaps in a large number of reports on differential mRNA expression after p53 induction, on the binding of DREAM components by ChIP, and whether the potential target genes display E2F or $\mathrm{CHR}$ elements. ${ }^{17,66}$ With a more recent analysis, the www.targetgenereg.org website was established. This site is updated with links to new data reports and allows retrieving results from genomewide analyses easily. ${ }^{65,67}$

Here, a compilation of p53-DREAM target genes is provided (Table 1). In order to obtain a catalog of highconfidence targets, criteria for inclusion as targets were binding of p130, E2F4, LIN9, LIN54, and the lack of binding by $\mathrm{p} 53$ as assayed by ChIP in combination with downregulation of target gene mRNA after activation of $p 53$. The data for individual genes were retrieved from www.targetgenereg.org and several meta-analyses. ${ }^{17,29,31,65-67}$ Although most of the p53-DREAM target genes were identified merely by such meta-analyses, several genes such as CCNB1, CDK1, CCNB2, KIF23, PLK4, BIRC5, CDC25C and PLK1 have already been found or confirmed in detailed experiments as targets of the p53-DREAM pathway. ${ }^{19,22,39,68,69}$ Nevertheless, meta-analyses of genome-wide studies bypass such experimental efforts for individual genes and yield more than 250 high-confidence p53-DREAM targets (Table 1).

The compilation of p53-DREAM targets represents numerous cellular functions (Table 1 and Figure 4). The many protein classes found among the p53-DREAM targets are illustrated by examples such as kinases, protein chaperones, DNA helicases, ubiquitin ligases, phosphatases, methyltransferases, nucleases, ATPases and transcription factors (Table 1). Most gene products participate in cell cycle control. Examples for particular functions are DNA replication, nucleosome packaging, mitotic spindle assembly and chromosome segregation. Thus, it is becoming evident that the p53-DREAM pathway coordinately downregulates a plethora of genes which are categorized into functional groups (Figure 4).

\section{Checkpoint Control from DNA Synthesis to Cytokinesis}

p53 can induce cell cycle arrest at several stages, including $\mathrm{G}_{1} / \mathrm{S}$ and $\mathrm{G}_{2} / \mathrm{M}$ checkpoints. ${ }^{1-4}$ For example, it has been shown that p53 can induce $G_{1}$ arrest via p21/CDKN1Adependent inhibition of cyclin A/E-CDK2. ${ }^{55}$ Also progression through $\mathrm{G}_{2}$ phase and mitosis can be affected by p53, as several early studies showed that p53 is responsible for the downregulation of many genes important for checkpoint control from $\mathrm{G}_{1}$ through cytokinesis. ${ }^{70-73}$ However, at the time it was not evident that such checkpoint control by p53 is based on a common mechanism ${ }^{17,39,66}$ (Figure 3). Now it is apparent that many proteins controlling cell cycle checkpoints are regulated by the p53-DREAM pathway and are clustered in functional groups (Table 1 and Figure 4).

\section{Coordinated Transcriptional Repression by the p53- DREAM Pathway}

A major feature of p53-dependent repression is that whole groups of functionally related genes are indirectly downregulated. Many such groups are defined by their function and timing of expression during the cell cycle. DREAM-dependent transcriptional repression employs binding to E2F or CHR sites as a determinant for early or late expression in the cell cycle, respectively. ${ }^{31,33}$ Genes with maximum expression in the $\mathrm{G}_{1}$ and $\mathrm{S}$ phases are controlled through E2F or E2F/CLE sites and can be activated by E2F1-3/DP complexes, whereas genes expressed in the $\mathrm{G}_{2}$ phase and mitosis are upregulated by MMB and FOXM1-MuvB activator complexes through CHR or CDE/CHR elements (Figure 1).

\section{$\mathrm{G}_{1} / \mathrm{S}$ Checkpoint Genes are Repressed by DREAM Binding to E2F Sites}

One group of DREAM target genes important for the $\mathrm{G}_{1} / \mathrm{S}$ checkpoint is represented by POLA1, MCM2 and ORC1 $1^{74,75}$ (Table 1). Furthermore, several DREAM targets, that is, cyclin $A, C D K 2, C D C 6$ and $C D T 1$, are active in a checkpoint preventing rereplication (Table 1). ${ }^{73,76}$ Interestingly, many genes previously described as classical E2F targets and hallmark genes for $S$ phase progression such as TK1 and 
Table 1 Genes regulated by the p53-DREAM pathway

\begin{tabular}{|c|c|c|c|c|}
\hline \multicolumn{5}{|c|}{ Genes regulated by the p53-DREAM pathway } \\
\hline Protein name & Protein & $\begin{array}{l}\text { Function, enzymatic } \\
\text { activity }\end{array}$ & GO - Gene Ontology & Gene \\
\hline $\begin{array}{l}\text { Adrenocortical dyspl. pr. hom., shelterin compl. sub. } \\
\text { telom. recruit. }\end{array}$ & ACD & $\begin{array}{l}\text { Complex form., DNA } \\
\text { binding }\end{array}$ & Telomere maintenance & ACD \\
\hline Anillin, actin-binding protein anillin & anillin & Actin binding & Mitosis & ANLN \\
\hline Rho GTPase-activating protein 11A & ARHGAP11A & $\begin{array}{l}\text { GTPase activator } \\
\text { activity }\end{array}$ & $\begin{array}{l}\text { Small GTPase-mediated signal } \\
\text { transduction }\end{array}$ & ARHGAP11A \\
\hline Rho GTPase-activating protein 11B & ARHGAP11B & $\begin{array}{l}\text { Rho GTPase } \\
\text { activation }\end{array}$ & $\begin{array}{l}\text { Small GTPase-mediated signal } \\
\text { transduction }\end{array}$ & ARHGAP11B \\
\hline $\begin{array}{l}\text { Rho guanine nucleotide exchange factor } 39 \text {, } \\
\text { C9orf100 }\end{array}$ & ARHGEF39 & $\begin{array}{l}\text { Rho guanyl- } \\
\text { nucleotide exch. }\end{array}$ & $\begin{array}{l}\text { Cell migration, Rho protein signal } \\
\text { transduction }\end{array}$ & ARHGEF39 \\
\hline ADP-ribosylation factor-like protein 13B & ARL13B & GTP binding & $\begin{array}{l}\text { Cilium assmb., small GTPase sig- } \\
\text { nal transduction }\end{array}$ & ARL13B \\
\hline $\begin{array}{l}\text { ADP-ribosylation factor-like protein 6-interacting } \\
\text { protein } 1\end{array}$ & ARL6IP1 & $\begin{array}{l}\text { Chromosomal pass. } \\
\text { complex }\end{array}$ & $\begin{array}{l}\text { Cotranslational protein targeting to } \\
\text { membrane }\end{array}$ & ARL6IP1 \\
\hline Anti-silencing function 1B histone chaperone & ASF1B & Histone chaperone & $\begin{array}{l}\text { Chromatin assembly, DNA } \\
\text { replication }\end{array}$ & ASF1B \\
\hline $\begin{array}{l}\text { Abnormal spindle-like microcephaly-associated } \\
\text { protein }\end{array}$ & ASPM & Complex formation & $\begin{array}{l}\text { Spindle assembly, mitosis, } \\
\text { neurogenesis }\end{array}$ & $\begin{array}{l}\text { ASPM, } \\
\text { MCPH5 }\end{array}$ \\
\hline ATPase family AAA domain-containing protein 2 & ATAD2 & ATPase & Transcriptional coactivator & ATAD2 \\
\hline Aurora kinase A & AURKA & $\begin{array}{l}\text { Serine/threonine } \\
\text { kinase }\end{array}$ & $\begin{array}{l}\text { Spindle/microtubule formation, } \\
\text { mitosis }\end{array}$ & AURKA \\
\hline Aurora kinase B & AURKB & $\begin{array}{l}\text { Serine/threonine } \\
\text { kinase }\end{array}$ & $\begin{array}{l}\text { Cytokinesis, histone modification, } \\
\text { mitosis }\end{array}$ & AURKB \\
\hline BLM, Bloom syndrome RecQ like helicase & BLM & DNA helicase & DNA replication and repair & BLM \\
\hline MYB proto-oncogene like 2 & $\begin{array}{l}\text { B-MYB, } \\
\text { MYBL2 }\end{array}$ & Transcription factor & S phase, activator & MYBL2 \\
\hline Borealin, CDCA8 & $\begin{array}{l}\text { Borealin, } \\
\text { CDCA8 }\end{array}$ & Complex formation & $\begin{array}{l}\text { Chromosomal passenger complex, } \\
\text { spindle form. }\end{array}$ & $\begin{array}{l}\text { CDCA8, } \\
\text { Borealin }\end{array}$ \\
\hline BRCA1, Breast cancer type 1 susceptibility protein & BRCA1 & Ubiquitin ligase & $\begin{array}{l}\text { DNA repair, transcription, } \\
\text { ubiquitination }\end{array}$ & $\begin{array}{l}\text { BRCA1, } \\
\text { FANCS }\end{array}$ \\
\hline BRCA2, Breast cancer type 2 susceptibility protein & BRCA2 & Complex formation & DNA repair, transcription & $\begin{array}{l}\text { BRCA2, } \\
\text { FANCD1 }\end{array}$ \\
\hline $\begin{array}{l}\text { BRIP1, BRCA1 interacting protein C-terminal heli- } \\
\text { case } 1\end{array}$ & $\begin{array}{l}\text { BRIP1, } \\
\text { BACH1 }\end{array}$ & $\begin{array}{l}\text { DNA helicase and } \\
\text { ATPase }\end{array}$ & DNA replication and repair & $\begin{array}{l}\text { BRIP1, } \\
\text { FANCJ }\end{array}$ \\
\hline BUB1, mitotic checkpoint serine/threonine kinase & BUB1 & $\begin{array}{l}\text { Serine/threonine } \\
\text { kinase }\end{array}$ & Spindle formation, mitosis & BUB1 \\
\hline BUB3, mitotic checkpoint protein & BUB3 & $\begin{array}{l}\text { Protein binding, WD } \\
\text { repeats }\end{array}$ & Spindle formation, mitosis & BUB3 \\
\hline BUB1, mitotic checkpoint serine/threonine kinase B & $\begin{array}{l}\text { BUBR1, } \\
\text { BUB1B }\end{array}$ & $\begin{array}{l}\text { Serine/threonine } \\
\text { kinase }\end{array}$ & Spindle formation, mitosis & $\begin{array}{l}\text { BUB1B, } \\
\text { BUBR1 }\end{array}$ \\
\hline Calcyclin-binding protein & CACYBP & Complex formation & $\begin{array}{l}\text { Ubiquitin-mediated degradation of } \\
\text { beta-catenin }\end{array}$ & CACYBP \\
\hline $\begin{array}{l}\text { Cancer susceptibility candidate } 5 \text {, Kinetochore-null } \\
\text { protein } 1\end{array}$ & CASC5, KNL1 & Protein binding & $\begin{array}{l}\text { Kinetochore, spindle formation, } \\
\text { mitosis }\end{array}$ & KNL1, CASC5 \\
\hline $\begin{array}{l}\text { Chromobox protein homolog } 3 \text {, Heterochromatin } \\
\text { prot. } 1 \text { hom. gam. }\end{array}$ & $\mathrm{CBX} 3, \mathrm{HECH}$ & Histone binding & $\begin{array}{l}\text { Transcription, histone methyltrans- } \\
\text { ferase binding }\end{array}$ & CBX3 \\
\hline Coiled-coil domain-containing protein 150 & CCDC150 & & & CCDC150 \\
\hline $\begin{array}{l}\text { Coiled-coil domain-containing protein 18, Sarco } \\
\text { antig NY-SAR-24 }\end{array}$ & CCDC18 & & & CCDC18 \\
\hline $\begin{array}{l}\text { Coiled-coil domain-containing protein } 34 \text {, Ren carc } \\
\text { ant NY-REN-41 }\end{array}$ & CCDC34 & & & CCDC34 \\
\hline CDC20, Cell division cycle protein 20 & $\begin{array}{l}\text { CDC20, } \\
\text { p55CDC }\end{array}$ & Complex formation & $\begin{array}{l}\text { mitotic spindle assembly check- } \\
\text { point, mitosis }\end{array}$ & $\begin{array}{l}\text { CDC20, } \\
\text { p55CDC }\end{array}$ \\
\hline $\begin{array}{l}\text { CDC20, cell division cycle 25A, M-phase inducer } \\
\text { phosphatase } 1\end{array}$ & CDC25A & $\begin{array}{l}\text { Tyrosine } \\
\text { phosphatase }\end{array}$ & G1/S and G2/M transition & CDC25A \\
\hline $\begin{array}{l}\text { CDC25B, Cell division cycle 25B, M-phase inducer } \\
\text { phosphatase } 2\end{array}$ & CDC25B & $\begin{array}{l}\text { Tyrosine } \\
\text { phosphatase }\end{array}$ & $\begin{array}{l}\text { G2/M phases and abscission during } \\
\text { cytokinesis }\end{array}$ & CDC25B \\
\hline $\begin{array}{l}\text { CDC25C, cell division cycle } 25 \text { C, M-phase inducer } \\
\text { phosphatase } 3\end{array}$ & CDC25C & $\begin{array}{l}\text { Tyrosine } \\
\text { phosphatase }\end{array}$ & $\begin{array}{l}\text { G2/M phases and abscission during } \\
\text { cytokinesis }\end{array}$ & CDC25C \\
\hline CDC6, cell division cycle 6 & CDC6 & & G1/S transition, DNA replication & CDC6 \\
\hline CDC7, cell division cycle 7 & CDC7 & Protein kinase & G1/S transition & CDC7 \\
\hline $\begin{array}{l}\text { CDCA2, cell division cycle-associated protein } 2 \text {, } \\
\text { Repo-Man }\end{array}$ & CDCA2 & Complex formation & Chromosome segregation & CDCA2 \\
\hline $\begin{array}{l}\text { Cell division cycle-assoc. prot. } 3 \text {, trigger of mitotic } \\
\text { entry protein } 1\end{array}$ & $\begin{array}{l}\text { CDCA3, } \\
\text { TOME-1 }\end{array}$ & F-box-like protein & Protein ubiquitination & $\begin{array}{l}\text { CDCA3, } \\
\text { TOME-1 }\end{array}$ \\
\hline CDK1, cyclin-dependent kinase 1, cdc2 & CDK1, CDC2 & $\begin{array}{l}\text { Serine/threonine } \\
\text { kinase }\end{array}$ & G1/S and G2/M transition & CDK1, CDC2 \\
\hline CDK2, cyclin-dependent kinase 2 & CDK2 & $\begin{array}{l}\text { Serine/threonine } \\
\text { kinase }\end{array}$ & G1/S and G2/M transition & CDK2 \\
\hline $\begin{array}{l}\text { CDKN2D, cyclin-dependent kinase } 4 \text { inhibitor D, } \\
\text { p19-INK4d }\end{array}$ & CDKN2D, p19 & CDK4/6 inhibitor & G1/S transition & CDKN2D \\
\hline
\end{tabular}


Table 1 (Continued)

\begin{tabular}{|c|c|c|c|c|}
\hline \multicolumn{5}{|c|}{ Genes regulated by the p53-DREAM pathway } \\
\hline Protein name & Protein & $\begin{array}{l}\text { Function, enzymatic } \\
\text { activity }\end{array}$ & GO - Gene Ontology & Gene \\
\hline $\begin{array}{l}\text { CDKN3, cyclin-dependent kinase inhibitor 3, CDI1, } \\
\text { CIP2, KAP }\end{array}$ & CDKN3, CIP2 & CDK2 phosphatase & $\begin{array}{l}\text { Regulation of cyclin-dependent } \\
\text { kinase activity }\end{array}$ & CDKN3 \\
\hline Chromatin licensing and DNA replication factor 1 & CDT1 & Chromatin binding & DNA replication, mitosis & CDT1 \\
\hline CENP-A, Histone H3-like centromeric protein A & CENP-A & Chromatin binding & $\begin{array}{l}\text { Nucleosome and kinetochore } \\
\text { assembly }\end{array}$ & CENPA \\
\hline CENP-C, centromere protein C & CENP-C & Kinetochore binding & $\begin{array}{l}\text { Microtubule function, cytokinesis, } \\
\text { mitosis }\end{array}$ & CENPC \\
\hline CENP-E, centromere protein E & CENP-E & Kinetochore binding & $\begin{array}{l}\text { Microtubule function, cytokinesis, } \\
\text { mitosis }\end{array}$ & CENPE \\
\hline CENP-F, centromere protein F, Mitosin & $\begin{array}{l}\text { CENP-F, } \\
\text { Mitosin }\end{array}$ & Kinetochore binding & $\begin{array}{l}\text { Microtubule function, cytokinesis, } \\
\text { mitosis }\end{array}$ & $\begin{array}{l}\text { CENPF, } \\
\text { CENF }\end{array}$ \\
\hline CENP-L, centromere protein $\mathrm{L}$ & $\begin{array}{l}\text { CENP-L, } \\
\text { ICEN33 }\end{array}$ & Chromatin binding & $\begin{array}{l}\text { Nucleosome and kinetochore } \\
\text { assembly }\end{array}$ & $\begin{array}{l}\text { CENPL, } \\
\text { ICEN33 }\end{array}$ \\
\hline CENP-N, centromere protein $\mathrm{N}$ & $\begin{array}{l}\text { CENP-N, } \\
\text { ICEN32 }\end{array}$ & Chromatin binding & $\begin{array}{l}\text { Nucleosome and kinetochore } \\
\text { assembly }\end{array}$ & $\begin{array}{l}\text { CENPN, } \\
\text { ICEN32 }\end{array}$ \\
\hline CENP-O, centromere protein $\mathrm{O}$ & CENP-O & Complex formation & $\begin{array}{l}\text { Nucleosome assembly, centro- } \\
\text { mere, mitosis }\end{array}$ & CENPO \\
\hline CENP-W, centromere protein $\mathrm{W}$ & CENP-W & Complex formation & $\begin{array}{l}\text { Nucleosome assembly, centro- } \\
\text { mere, mitosis }\end{array}$ & CENPW \\
\hline CEP55, centrosomal protein of $55 \mathrm{kDa}$ & CEP55 & Complex formation & $\begin{array}{l}\text { Mitotic exit, cell separation after } \\
\text { cytokinesis }\end{array}$ & CEP55 \\
\hline CEP152, centrosomal protein of $152 \mathrm{kDa}$ & CEP152 & $\begin{array}{l}\text { Protein kinase } \\
\text { binding }\end{array}$ & $\begin{array}{l}\text { Centriole and centrosome } \\
\text { duplication }\end{array}$ & CEP152 \\
\hline CEP295, centrosomal protein 295, DD8 & CEP295, DD8 & Complex formation & $\begin{array}{l}\text { centrosome, microtubules, cytos- } \\
\text { keleton, cilium }\end{array}$ & $\begin{array}{l}\text { CEP295, } \\
\text { KIAA1731 }\end{array}$ \\
\hline CHAF1A, chromatin assembly factor 1 subunit A & CHAF1A & Histone binding & $\begin{array}{l}\text { Histone octamer assembly, chro- } \\
\text { matin, replicat. }\end{array}$ & CHAF1A \\
\hline CHEK1, checkpoint kinase 1 & CHEK1 & $\begin{array}{l}\text { Serine/threonine } \\
\text { kinase }\end{array}$ & $\begin{array}{l}\text { DNA damage response, G2/M } \\
\text { transition }\end{array}$ & CHEK1 \\
\hline CHEK2, checkpoint kinase 2 & CHEK2 & $\begin{array}{l}\text { Serine/threonine } \\
\text { kinase }\end{array}$ & $\begin{array}{l}\text { DNA damage response, G2/M } \\
\text { transition }\end{array}$ & CHEK2 \\
\hline $\begin{array}{l}\text { CIP2A, cancerous inhibitor of protein phosphatase } \\
2 \mathrm{~A}\end{array}$ & CIP2A & Phosphatase inhibitor & $\begin{array}{l}\text { Oncoprotein, cell adhesion, } \\
\text { transcription }\end{array}$ & $\begin{array}{l}\text { KIAA1524, } \\
\text { CIP2A }\end{array}$ \\
\hline CIT, Citron Rho-interacting kinase & CIT, CRIK & $\begin{array}{l}\text { Serine/threonine } \\
\text { kinase }\end{array}$ & $\begin{array}{l}\text { Cytokinesis, GTPase signal } \\
\text { transduction }\end{array}$ & CIT, CRIK \\
\hline $\begin{array}{l}\text { Cytoskeleton-associated protein } 2 \text {, tumor- and } \\
\text { microtub.-assoc. }\end{array}$ & CKAP2, TMAP & $\begin{array}{l}\text { Microtubule } \\
\text { stabilizing }\end{array}$ & $\begin{array}{l}\text { Apoptotic process, microtubule } \\
\text { polymerization }\end{array}$ & CKAP2 \\
\hline $\begin{array}{l}\text { CKAP2L, cytoskeleton-associated protein 2-like, } \\
\text { Radmis }\end{array}$ & $\begin{array}{l}\text { CKAP2L, } \\
\text { Radmis }\end{array}$ & Complex formation & $\begin{array}{l}\text { Microtubule bundles, centrioles } \\
\text { during mitosis }\end{array}$ & CKAP2L \\
\hline CKAP5, cytoskeleton-associated protein 5 & CKAP5 & Microtubule binding & $\begin{array}{l}\text { Microtubule cytoskeleton polarity, } \\
\text { spindle pole }\end{array}$ & CKAP5 \\
\hline $\begin{array}{l}\text { Cyclin-dependent kinases regulatory subunit 1, } \\
\text { CDC28 kin sub 1B }\end{array}$ & $\begin{array}{l}\text { CKS-1, } \\
\text { CKS-1B }\end{array}$ & $\begin{array}{l}\text { Cyclin-dep. kinase } \\
\text { binding }\end{array}$ & G1/S transition, CDK binding & $\begin{array}{l}\text { CKS1B, } \\
\text { CKS1 }\end{array}$ \\
\hline $\begin{array}{l}\text { CKS-2, cyclin-dependent kinases regulatory sub- } \\
\text { unit } 2\end{array}$ & CKS-2 & $\begin{array}{l}\text { Cyclin-dep. kinase } \\
\text { binding }\end{array}$ & Meiosis I, CDK binding & CKS2 \\
\hline CMS1, ribosomal small subunit homolog & $\begin{array}{l}\text { CMSS1, } \\
\text { CMS1 }\end{array}$ & Poly (A) RNA binding & Poly(A) RNA binding & CMSS1 \\
\hline CTD small phosphatase-like protein 2 & CTDSPL2 & Protein phosphatase & $\begin{array}{l}\text { BMP signaling pathway, transport } \\
\text { from nucleus }\end{array}$ & CTDSPL2 \\
\hline Cyclin A & $\begin{array}{l}\text { Cyclin A, cyclin } \\
\text { A2 }\end{array}$ & Complex formation & $\begin{array}{l}\text { Serine/threonine kinase activation, } \\
\text { mitosis }\end{array}$ & CCNA, Ccna2 \\
\hline Cyclin B1 & cyclin B1 & Complex formation & $\begin{array}{l}\text { Serine/threonine kinase activation, } \\
\text { mitosis }\end{array}$ & CCNB1 \\
\hline Cyclin B2 & Cyclin B2 & Complex formation & $\begin{array}{l}\text { Serine/threonine kinase activation, } \\
\text { mitosis }\end{array}$ & CCNB2 \\
\hline DAP-5, Disks large-associated protein 5 & $\begin{array}{l}\text { DAP-5, } \\
\text { DLGAP5 }\end{array}$ & & $\begin{array}{l}\text { Metaphase/anaphase transition, } \\
\text { ubiqutination }\end{array}$ & $\begin{array}{l}\text { DLGAP5, } \\
\text { DLG7 }\end{array}$ \\
\hline DARS2, Aspartate-tRNA ligase, mitochondrial & DARS2 & $\begin{array}{l}\text { Aspartate-tRNA } \\
\text { ligase }\end{array}$ & $\begin{array}{l}\text { Gene expression, aminoacylation } \\
\text { for translation }\end{array}$ & DARS2 \\
\hline $\begin{array}{l}\text { Protein DBF4 homolog B, activator of S phase } \\
\text { kinase-like prot. } 1\end{array}$ & $\begin{array}{l}\text { DBF4B, } \\
\text { ASKL1 }\end{array}$ & $\begin{array}{l}\text { CDC7 kinase } \\
\text { activation }\end{array}$ & DNA replication, G2/M transition & DBF4B, DRF1 \\
\hline DCAF16, DDB1- and CUL4-associated factor 16 & DCAF16 & Protein ubiquitination & Protein ubiquitination & DCAF16 \\
\hline DCK, deoxycytidine kinase & DCK & Nucleoside kinase & Nucleotide biosynthetic process & DCK \\
\hline DCLRE1B, $5^{\prime}$ exonuclease Apollo & $\begin{array}{l}\text { DCLRE1B, } \\
\text { APOLLO }\end{array}$ & $\begin{array}{l}5^{\prime}-3^{\prime} \text { DNA } \\
\text { exonuclease }\end{array}$ & $\begin{array}{l}\text { Telomere maintenance, double- } \\
\text { strand br. rep. }\end{array}$ & DCLRE1B \\
\hline DCP2, m7GpppN-mRNA hydrolase & DCP2 & $\begin{array}{l}\text { mRNA-decapping } \\
\text { enzyme }\end{array}$ & $\begin{array}{l}\text { Regulation of mRNA stability, gene } \\
\text { expression }\end{array}$ & DCP2 \\
\hline $\begin{array}{l}\text { DNA damage-induced apoptosis suppressor, NO- } \\
\text { inducible prot. }\end{array}$ & $\begin{array}{l}\text { DDIAS, } \\
\text { NOXIN }\end{array}$ & & Apoptosis, DNA damage resp., cell & DDIAS, \\
\hline DDX10, ATP-dependent RNA helicase DDX10 & DDX10 & RNA helicase & & $\begin{array}{l}\text { NOXIN } \\
\text { DDX10 }\end{array}$ \\
\hline
\end{tabular}


Table 1 (Continued)

\begin{tabular}{|c|c|c|c|c|}
\hline \multicolumn{5}{|c|}{ Genes regulated by the p53-DREAM pathway } \\
\hline Protein name & Protein & $\begin{array}{l}\text { Function, enzymatic } \\
\text { activity }\end{array}$ & GO - Gene Ontology & Gene \\
\hline & & & $\begin{array}{l}\text { RNA secondary structure } \\
\text { unwinding }\end{array}$ & \\
\hline DEK, proto-oncogene & DEK & Histone binding & $\begin{array}{l}\text { Chromatin modification, mRNA } \\
\text { processing }\end{array}$ & DEK \\
\hline DEPDC1, DEP domain-containing protein 1A & DEPDC1 & $\begin{array}{l}\text { Transcriptional } \\
\text { corepressor }\end{array}$ & $\begin{array}{l}\text { GTPase activator activity, } \\
\text { transcription }\end{array}$ & DEPDC1 \\
\hline DEPDC1B, DEP domain-containing protein 1B & DEPDC1B & $\begin{array}{l}\text { GTPase activator } \\
\text { activity }\end{array}$ & $\begin{array}{l}\text { Cell migration, Wnt signaling path- } \\
\text { way, GTPase }\end{array}$ & $\begin{array}{l}\text { DEPDC1B, } \\
\text { XTP1 }\end{array}$ \\
\hline Dihydrofolate reductase & DHFR & Oxidoreductase & DNA synthesis & DHFR \\
\hline DLEU1, Leukemia-associated protein 1 & DLEU1 & & & DLEU1, XTP6 \\
\hline DNMt3B, DNA methyltransferase 3 beta & DNMT3B & Methyltransferase & $\begin{array}{l}\text { Chromatin binding, transcriptional } \\
\text { corepressor }\end{array}$ & DNMT3B \\
\hline E2F1, E2F transcription factor 1 & E2F1 & Transcription factor & Cell cycle & E2F1 \\
\hline ECT2, epithelial cell transforming 2 & ECT2 & GTPase & $\begin{array}{l}\text { Cytokinesis, spindle formation, } \\
\text { mitosis }\end{array}$ & ECT2 \\
\hline $\begin{array}{l}\text { establishment of sister chromatid cohesion } N \text { - } \\
\text { acetyltransferase } 2\end{array}$ & ESCO2 & $\begin{array}{l}\text { Lysine } \\
\text { N-acetyltransferase }\end{array}$ & Chromosome segregation & ESCO2 \\
\hline EXO1, Exonuclease 1 & EXO1 & DNA nuclease & $\begin{array}{l}\text { DNA repair, recombination, } \\
\text { replication }\end{array}$ & EXO1 \\
\hline EXOSC8, exosome component 8 & EXOSC8 & Exoribonuclease & RNA degradation & EXOSC8 \\
\hline EXOSC9, exosome component 9 & EXOSC9 & Complex formation & RNA degradation & EXOSC9 \\
\hline Exportin-2, CSE1 chromosome segregation 1-like & Exportin-2 & $\begin{array}{l}\text { Export receptor } \\
\text { importin-a }\end{array}$ & Protein transport from/to nucleus & CSE1L \\
\hline $\begin{array}{l}\text { Histone-lysine } \mathrm{N} \text {-methyltransferase, enhancer of } \\
\text { zeste } 2 \text { polycomb }\end{array}$ & $\mathrm{EZH} 2$ & $\begin{array}{l}\text { Lysine } N \text { - } \\
\text { methyltransferase }\end{array}$ & $\begin{array}{l}\text { Histone modification, chromatin } \\
\text { organization }\end{array}$ & $\mathrm{EZH} 2$ \\
\hline $\begin{array}{l}\text { FAM64A, family with sequence similarity } 64 \text { mem- } \\
\text { ber A }\end{array}$ & FAM64A & Complex formation & Mitosis & FAM64A \\
\hline $\begin{array}{l}\text { FAM83D, family with sequence similarity } 83 \text { mem- } \\
\text { ber D }\end{array}$ & FAM83D & Complex formation & Mitosis & FAM83D \\
\hline FANCA, Fanconi anemia complementation group A & FANCA & Complex formation & Fanconi anemia, DNA repair & FANCA \\
\hline FANCB, Fanconi anemia complementation group B & FANCB & Complex formation & Fanconi anemia, DNA repair & FANCB \\
\hline FANCC, Fanconi anemia complementation group C & FANCC & Complex formation & Fanconi anemia, DNA repair & FANCC \\
\hline $\begin{array}{l}\text { FANCD2, Fanconi anemia complementation group } \\
\text { D2 }\end{array}$ & FANCD2 & Complex formation & Fanconi anemia, DNA repair & FANCD2 \\
\hline FANCE, Fanconi anemia complementation group E & FANCE & Complex formation & Fanconi anemia, DNA repair & FANCE \\
\hline FANCG, Fanconi anemia complementation group $\mathrm{G}$ & FANCG & Complex formation & Fanconi anemia, DNA repair & FANCG \\
\hline FANCI, Fanconi anemia complementation group I & $\mathrm{FANCl}$ & $\begin{array}{l}\text { DNA binding, com- } \\
\text { plex form. }\end{array}$ & Fanconi anemia, DNA repair & $\mathrm{FANCl}$ \\
\hline FANCL, Fanconi anemia complementation group L & FANCL & Ubiquitin ligase & Fanconi anemia, DNA repair & FANCL \\
\hline $\begin{array}{l}\text { FANCM, Fanconi anemia complementation group } \\
\text { M }\end{array}$ & FANCM & ATPase, DNA binding & $\begin{array}{l}\text { Fanconi anemia, ubiquitination, } \\
\text { DNA repair }\end{array}$ & FANCM \\
\hline $\begin{array}{l}\text { FBXO5, F-box protein 5, Early mitotic inhibitor 1, } \\
\text { EMI1, FBX5 }\end{array}$ & FBXO5 & Complex formation & Mitosis & FBXO5 \\
\hline FEN1, flap structure-specific endonuclease 1 & FEN1 & DNA nuclease & DNA repair & FEN1, RAD2 \\
\hline FOXM1, forkhead box M1 & FOXM1 & Transcription factor & G2 phase, mitosis, activator & FOXM1 \\
\hline FZR1, fizzy/cell division cycle 20 related 1 & FZR1 & $\begin{array}{l}\text { Activator of } \\
\text { ubiquitination }\end{array}$ & $\begin{array}{l}\text { Mitosis, anaphase promoting com- } \\
\text { plex/cyclos. }\end{array}$ & FZR1 \\
\hline $\begin{array}{l}\text { G2E3, G2/M-phase specific E3 ubiquitin protein } \\
\text { ligaseprovided }\end{array}$ & G2E3 & Ubiquitin ligase & G2 phase, mitosis & G2E3 \\
\hline GASL2L3, growth arrest specific 2 like 3 & GAS2L3 & Complex formation & Cytokinesis & GAS2L3 \\
\hline GPSM2, G-protein signaling modulator 2provided & GPSM2 & $\begin{array}{l}\text { GDP-dissociation } \\
\text { inhibitor }\end{array}$ & $\begin{array}{l}\text { G-protein coupled receptor sign., } \\
\text { mitotic spindle }\end{array}$ & GPSM2 \\
\hline GTSE1, G2 and S-phase expressed 1 & GTSE1 & Complex formation & Microtubule organization & GTSE1 \\
\hline histone, $\mathrm{H} 2 \mathrm{~A}$ histone family member $\mathrm{X}$ & H2AFX, H2AX & Histone & Nucleosome formation, DNA repair & H2AFX \\
\hline histone, H2A histone family member $\mathrm{Z}$ & H2AFZ, H2AZ & Histone & $\begin{array}{l}\text { Nucleosome formation, embryonic } \\
\text { development }\end{array}$ & H2AFZ \\
\hline haspin, germ cell associated 2 & haspin, GSG2 & $\begin{array}{l}\text { Serine/threonine } \\
\text { kinase }\end{array}$ & Mitosis, microtubule organization & GSG2 \\
\hline HAUS augmin like complex subunit 6 & HAUS6 & Complex formation & Cytokinesis, spindle assembly & HAUS6 \\
\hline HAUS augmin like complex subunit 8 & $\begin{array}{l}\text { HAUS8, } \\
\text { HICE1 }\end{array}$ & Complex formation & Cytokinesis, spindle assembly & HAUS8 \\
\hline histone cluster $1 \mathrm{H} 2 \mathrm{~A}$ family member e & $\begin{array}{l}\text { HIST } 1 \text { H2AE, } \\
\text { H2A.1 }\end{array}$ & Histone & Nucleosome formation & HIST1H2AE \\
\hline histone cluster $1 \mathrm{H} 2 \mathrm{~A}$ family member m & HIST1H2AM & Histone & Nucleosome formation & HIST1H2AM \\
\hline histone cluster $1 \mathrm{H} 2 \mathrm{~B}$ family member $\mathrm{f}$ & HIST1H2BF & Histone & Nucleosome formation & HIST1H2BF \\
\hline histone cluster $1 \mathrm{H} 2 \mathrm{~B}$ family member $\mathrm{h}$ & HIST1H2BH & Histone & Nucleosome formation & HIST1H2BH \\
\hline histone cluster $1 \mathrm{H} 2 \mathrm{~B}$ family member i & HIST1H2BI & Histone & Nucleosome formation & HIST1H2BI \\
\hline histone cluster $1 \mathrm{H} 2 \mathrm{~B}$ family member $\mathrm{m}$ & HIST1H2BM & Histone & Nucleosome formation & HIST1H2BM \\
\hline histone cluster $1 \mathrm{H} 3$ family member $\mathrm{c}$ & HIST1H3C & Histone & Nucleosome formation & HIST1H3C \\
\hline histone cluster $1 \mathrm{H} 3$ family member $\mathrm{d}$ & HIST1H3D & Histone & Nucleosome formation & HIST1H3D \\
\hline
\end{tabular}


Table 1 (Continued)

\begin{tabular}{|c|c|c|c|c|}
\hline \multicolumn{5}{|c|}{ Genes regulated by the p53-DREAM pathway } \\
\hline Protein name & Protein & $\begin{array}{l}\text { Function, enzymatic } \\
\text { activity }\end{array}$ & GO - Gene Ontology & Gene \\
\hline histone cluster $1 \mathrm{H} 4$ family member $\mathrm{c}$ & HIST1H4C & Histone & Nucleosome formation & HIST1H4C \\
\hline histone cluster $2 \mathrm{H} 2 \mathrm{~A}$ family member $\mathrm{b}$ & HIST2H2AB & Histone & Nucleosome formation & HIST2H2AB \\
\hline histone cluster $2 \mathrm{H} 2 \mathrm{~A}$ family member $\mathrm{c}$ & HIST2H2AC & Histone & Nucleosome formation & HIST2H2AC \\
\hline Holliday junction recognition protein & HJURP & $\begin{array}{l}\text { DNA binding, } \\
\text { chaperone }\end{array}$ & Centromere, nucleosome assembly & HJURP \\
\hline HMGB2, High mobility group protein B2 & $\begin{array}{l}\text { HMGB2, } \\
\text { HMG2 }\end{array}$ & DNA binding & $\begin{array}{l}\text { Chromatin, transcription, } \\
\text { recombination }\end{array}$ & HMGB2 \\
\hline $\begin{array}{l}\text { HMMR, Receptor for hyaluronan-med. motility, } \\
\text { RHAMM, CD168 }\end{array}$ & $\begin{array}{l}\text { HMMR, } \\
\text { RHAMM }\end{array}$ & Complex formation & $\begin{array}{l}\text { Cell adhesion, mitosis, hyaluronic } \\
\text { acid binding }\end{array}$ & $\begin{array}{l}\text { HMMR, } \\
\text { RHAMM }\end{array}$ \\
\hline $\begin{array}{l}\text { HNRNPAO, heterogeneous nuclear ribonucleopro- } \\
\text { tein AO }\end{array}$ & HNRNPAO & RNA binding & mRNA processing & HNRNPAO \\
\hline $\begin{array}{l}\text { HNRNPA2B1, heterogeneous nuclear ribonucleo- } \\
\text { protein A2/B1 }\end{array}$ & hnRNP A2/B1 & RNA binding & $\begin{array}{l}\text { RNA and single-stranded telomeric } \\
\text { DNA binding }\end{array}$ & HNRNPA2B1 \\
\hline $\begin{array}{l}\text { BORA, Aurora kinase A activator, protein aurora } \\
\text { borealis }\end{array}$ & HsBora & Kinase binding & $\begin{array}{l}\text { Spindle/microtubule formation, } \\
\text { mitosis }\end{array}$ & BORA \\
\hline IFT80, intraflagellar transport 80 & IFT80 & Complex formation & Cilia assembly & IFT80 \\
\hline INCENP, inner centromere protein & INCENP & Complex formation & $\begin{array}{l}\text { Cytokinesis, centromere, microtu- } \\
\text { bule binding }\end{array}$ & INCENP \\
\hline ING1, inhibitor of growth family member 1 & ING1 & Complex formation & $\begin{array}{l}\text { p53 interaction, tumor suppr., } \\
\text { chromatin }\end{array}$ & ING1 \\
\hline 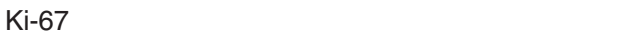 & Ki-67 & Complex formation & Mitotic chromosome stabilization & MKI67 \\
\hline KIF11, kinesin family member 11 & KIF11, EG5 & Microtubule binding & $\begin{array}{l}\text { Microtubule function, cytokinesis, } \\
\text { mitosis }\end{array}$ & KIF11, EG5 \\
\hline KIF14, kinesin family member 14 & KIF14 & Microtubule binding & $\begin{array}{l}\text { Microtubule function, cytokinesis, } \\
\text { mitosis }\end{array}$ & KIF14 \\
\hline KIF15, kinesin family member 15 & KIF15 & Microtubule binding & $\begin{array}{l}\text { Microtubule function, cytokinesis, } \\
\text { mitosis }\end{array}$ & KIF15 \\
\hline KIF18A, kinesin family member $18 \mathrm{~A}$ & KIF18A & Microtubule binding & $\begin{array}{l}\text { Microtubule function, cytokinesis, } \\
\text { mitosis }\end{array}$ & KIF18A \\
\hline $\begin{array}{l}\text { KIF20B, kinesin family member 20B, M-phase } \\
\text { phosphoprotein-1 }\end{array}$ & KIF20B, MPP1 & Microtubule binding & $\begin{array}{l}\text { Microtubule function, cytokinesis, } \\
\text { mitosis }\end{array}$ & $\begin{array}{l}\text { KIF20B, } \\
\text { MPP1 }\end{array}$ \\
\hline KIF22, kinesin family member 22 & KIF22, KID & Microtubule binding & $\begin{array}{l}\text { Microtubule function, cytokinesis, } \\
\text { mitosis }\end{array}$ & KIF22, KID \\
\hline $\begin{array}{l}\text { KIF23, kinesin family member } 23 \text {, Mitotic kinesin- } \\
\text { like protein } 1\end{array}$ & KIF23, MKLP1 & Microtubule binding & $\begin{array}{l}\text { Microtubule function, cytokinesis, } \\
\text { mitosis }\end{array}$ & $\begin{array}{l}\text { KIF23, } \\
\text { MKLP1 }\end{array}$ \\
\hline KIF24, kinesin family member 24 & KIF24 & Microtubule binding & $\begin{array}{l}\text { Microtubule function, cytokinesis, } \\
\text { mitosis }\end{array}$ & KIF24 \\
\hline $\begin{array}{l}\text { KIF2C, kinesin family member } 2 \text { C, Mitotic } \\
\text { centromere-ass. kinesin }\end{array}$ & KIF2C, MCAK & Microtubule binding & $\begin{array}{l}\text { Microtubule function, cytokinesis, } \\
\text { mitosis }\end{array}$ & KIF2C \\
\hline KIF4A, kinesin family member $4 \mathrm{~A}$ & KIF4A, KIF4 & Microtubule binding & $\begin{array}{l}\text { Microtubule function, cytokinesis, } \\
\text { mitosis }\end{array}$ & KIF4A \\
\hline KIFC1, kinesin family member C1 & KIFC1 & ATPase & $\begin{array}{l}\text { Microtubule motor activity, spindle } \\
\text { assembly }\end{array}$ & KIFC1 \\
\hline $\begin{array}{l}\text { KPNA2, Importin subunit alpha-1, karyopherin } \\
\text { subunit alpha } 2\end{array}$ & KPNA2 & Protein transporter & $\begin{array}{l}\text { Nuclear protein import, } \\
\text { recombination }\end{array}$ & KPNA2 \\
\hline $\begin{array}{l}\text { KPNB1, Importin subunit beta-1, karyopherin sub- } \\
\text { unit beta } 2\end{array}$ & KPNB1 & Protein transporter & Nuclear protein import & KPNB1 \\
\hline lamin B1 & lamin B1 & Lamin & Nuclear lamina & LMNB1 \\
\hline $\begin{array}{l}\text { Acidic leucine-rich nuclear phosphoprotein } 32 \\
\text { family member } \mathrm{E}\end{array}$ & $\begin{array}{l}\text { LANP-like } \\
\text { protein }\end{array}$ & Histone chaperone & $\begin{array}{l}\text { Histone exchange, chromatin } \\
\text { modification }\end{array}$ & ANP32E \\
\hline LIN-54 DREAM MuvB core complex component & LIN54 & DNA binding & $\begin{array}{l}\text { Transcription, activator, repessor, } \\
\text { cell cycle }\end{array}$ & LIN54 \\
\hline LIN-9 DREAM MuvB core complex component & LIN9 & $\begin{array}{l}\text { complex, } \\
\text { transcription }\end{array}$ & $\begin{array}{l}\text { transcription, activator, repessor, } \\
\text { cell cycle }\end{array}$ & LIN9 \\
\hline LSM5, U6 snRNA-associated Sm-like protein LSm5 & LSM5 & RNA binding & mRNA processing & LSM5 \\
\hline $\begin{array}{l}\text { MAD2, Mitotic spindle assembly checkpoint protein } \\
\text { MAD2A }\end{array}$ & MAD2 & Complex formation & $\begin{array}{l}\text { Mitotic spindle assembly check- } \\
\text { point, mitosis }\end{array}$ & $\begin{array}{l}\text { MAD2L1, } \\
\text { MAD2 }\end{array}$ \\
\hline MAD3, Max dimerization protein 3 & MAD3, MXD3 & Transcription factor & MYC/MAX-related, repressor & MXD3 \\
\hline $\begin{array}{l}\text { GREATWALL, microtubule associated serine/ } \\
\text { threonine kinase like }\end{array}$ & MASTL & $\begin{array}{l}\text { Serine/threonine } \\
\text { kinase }\end{array}$ & G2 phase, mitosis & MASTL \\
\hline $\begin{array}{l}\text { MCM2, minichromosome maintenance complex } \\
\text { component } 2\end{array}$ & MCM2 & $\begin{array}{l}\text { Complex formation, } \\
\text { ATPase }\end{array}$ & DNA helicase, replication & MCM2 \\
\hline $\begin{array}{l}\text { MCM3, minichromosome maintenance complex } \\
\text { component } 3 \text {, HCC5 }\end{array}$ & MCM3, HCC5 & $\begin{array}{l}\text { Complex formation, } \\
\text { ATPase }\end{array}$ & DNA helicase, replication & MCM3 \\
\hline $\begin{array}{l}\text { MCM4, minichromosome maintenance complex } \\
\text { component } 4\end{array}$ & MCM4 & $\begin{array}{l}\text { Complex formation, } \\
\text { ATPase }\end{array}$ & DNA helicase, replication & MCM4 \\
\hline $\begin{array}{l}\text { MCM5, minichromosome maintenance complex } \\
\text { comp. } 5 \text {, CDC } 46\end{array}$ & $\begin{array}{l}\text { MCM5, } \\
\text { CDC46 }\end{array}$ & $\begin{array}{l}\text { Complex formation, } \\
\text { ATPase }\end{array}$ & DNA helicase, replication & MCM5 \\
\hline $\begin{array}{l}\text { MCM6, minichromosome maintenance complex } \\
\text { component } 6 \text {, Mis5 }\end{array}$ & MCM6, Mis5 & $\begin{array}{l}\text { Complex formation, } \\
\text { ATPase }\end{array}$ & DNA helicase, replication & MCM6 \\
\hline
\end{tabular}


Table 1 (Continued)

\begin{tabular}{|c|c|c|c|c|}
\hline \multicolumn{5}{|c|}{ Genes regulated by the p53-DREAM pathway } \\
\hline Protein name & Protein & $\begin{array}{l}\text { Function, enzymatic } \\
\text { activity }\end{array}$ & GO - Gene Ontology & Gene \\
\hline $\begin{array}{l}\text { MCM7, minichromosome maintenance complex } \\
\text { comp. } 7, \text { CDC47 }\end{array}$ & $\begin{array}{l}\text { MCM7 } \\
\text { CDC47 }\end{array}$ & $\begin{array}{l}\text { Complex formation, } \\
\text { ATPase }\end{array}$ & DNA helicase, replication & MCM7 \\
\hline $\begin{array}{l}\text { MCM8, minichromosome mainten. } 8 \text { homolog. } \\
\text { recomb. repair factor }\end{array}$ & MCM8 & $\begin{array}{l}\text { Complex formation, } \\
\text { ATPase }\end{array}$ & $\begin{array}{l}\text { Helicase, replication, homolog. } \\
\text { recomb. repair }\end{array}$ & MCM8 \\
\hline MDC1, mediator of DNA damage checkpoint 1 & MDC1 & Complex formation & $\begin{array}{l}\text { DNA repair, checkpoint control, S, } \\
\text { G2, M phase }\end{array}$ & MDC1 \\
\hline MELK1, maternal embryonic leucine zipper kinase & MELK & $\begin{array}{l}\text { Serine/threonine } \\
\text { kinase }\end{array}$ & Apoptosis, G2/M transition & MELK \\
\hline METTL4, methyltransferase like 4 & METTL4 & $\begin{array}{l}\text { DNA } \\
\text { Methyltransferase }\end{array}$ & DNA methylation, adenine-specific & METTL4 \\
\hline MIS18, kinetochore protein A & MIS18A & Complex formation & $\begin{array}{l}\text { Centromere complexes, chromo- } \\
\text { some segregat. }\end{array}$ & MIS18A \\
\hline MIS18BP1, MIS18 binding protein 1 & MIS18BP1 & Complex formation & $\begin{array}{l}\text { Centromere complexes, chromo- } \\
\text { some segregat. }\end{array}$ & MIS18BP1 \\
\hline MND1, meiotic nuclear divisions 1 & MND1 & DNA binding & Meiosis, DNA recombination & MND1 \\
\hline $\begin{array}{l}\text { MSH2, mutS homolog 2, Heredit. non-polyp. color. } \\
\text { Canc. 1, HNPCC }\end{array}$ & $\mathrm{MSH} 2$ & $\begin{array}{l}\text { Complex formation, } \\
\text { ATPase }\end{array}$ & DNA repair, mismatch repair & $\begin{array}{l}\text { MSH2, } \\
\text { HNPCC }\end{array}$ \\
\hline MSH6, mutS homolog 6 & MSH6 & $\begin{array}{l}\text { Complex formation, } \\
\text { ATPase }\end{array}$ & DNA repair, mismatch repair & MSH6 \\
\hline $\begin{array}{l}\text { metal response element bind. transcription fact. } 2 \text {, } \\
\text { polycomblike } 2\end{array}$ & MTF2, PCL2 & DNA binding & $\begin{array}{l}\text { Histone binding, transcription, } \\
\text { repression }\end{array}$ & MTF2 \\
\hline MZT1, Mitotic-spindle organizing protein 1 & $\begin{array}{l}\text { MZT1, } \\
\text { MOZART1 }\end{array}$ & Complex formation & $\begin{array}{l}\text { Tubulin binding, centrosome, spin- } \\
\text { dle assembly }\end{array}$ & MZT1 \\
\hline NASP, nuclear autoantigenic sperm protein & NASP & Histone binding & DNA replication & NASP \\
\hline $\begin{array}{l}\text { NCAPD2, condensin, non-SMC condensin I com- } \\
\text { plex subunit D2 }\end{array}$ & NCAPD2 & Complex formation & $\begin{array}{l}\text { Chromosome condensation, } \\
\text { mitosis }\end{array}$ & NCAPD2 \\
\hline $\begin{array}{l}\text { NCAPD3, condensin, non-SMC condensin II com- } \\
\text { plex subunit D3 }\end{array}$ & NCAPD3 & Complex formation & $\begin{array}{l}\text { Chromosome condensation, } \\
\text { mitosis }\end{array}$ & NCAPD3 \\
\hline $\begin{array}{l}\text { NCAPG, condensin, non-SMC condensin I complex } \\
\text { subunit G }\end{array}$ & NCAPG & Complex formation & $\begin{array}{l}\text { Chromosome condensation, } \\
\text { mitosis }\end{array}$ & NCAPG \\
\hline $\begin{array}{l}\text { NCAPG2, condensin, non-SMC condensin II com- } \\
\text { plex subunit G2 }\end{array}$ & NCAPG2 & Complex formation & $\begin{array}{l}\text { Chromosome condensation, } \\
\text { mitosis }\end{array}$ & NCAPG2 \\
\hline $\begin{array}{l}\text { NCAPH, condensin, non-SMC condensin I complex } \\
\text { subunit H }\end{array}$ & NCAPH & Complex formation & $\begin{array}{l}\text { Chromosome condensation, } \\
\text { mitosis }\end{array}$ & $\mathrm{NCAPH}$ \\
\hline NDC1, transmembrane nucleoporin & $\begin{array}{l}\text { NDC1, } \\
\text { TMEM48 }\end{array}$ & Complex formation & $\begin{array}{l}\text { Nuclear envelope assembly, } \\
\text { nuclear transport }\end{array}$ & $\begin{array}{l}\text { NDC1, } \\
\text { TMEM48 }\end{array}$ \\
\hline NDC80, kinetochore complex component NDC80 & NDC80 & Complex formation & $\begin{array}{l}\text { Chromosome segregation, micro- } \\
\text { tubule binding }\end{array}$ & NDC80 \\
\hline NEIL3, nei like DNA glycosylase 3 & NEIL3 & DNA endonuclease & DNA repair & NEIL3 \\
\hline NEK2, NIMA related kinase 2 & NEK2 & $\begin{array}{l}\text { Serine/threonine } \\
\text { kinase }\end{array}$ & $\begin{array}{l}\text { Chromosome condensation, spin- } \\
\text { dle assembly }\end{array}$ & NEK2 \\
\hline NET1, neuroepithelial cell transforming 1 & NET1 & $\begin{array}{l}\text { Rho guanyl- } \\
\text { nucleotide exch. }\end{array}$ & Apoptosis, signal transduction & NET1 \\
\hline NOP58, ribonucleoprotein & NOP58 & Complex formation & Ribosome biogenesis & NOP58 \\
\hline NOXIN, DNA damage-induced apoptosis & NOXIN, & & Apoptosis, response to DNA & C11orf82, \\
\hline suppressor & DDIAS & & damage, mitosis & DDIAS \\
\hline $\begin{array}{l}\text { nuclear casein kinase and cyclin-dependent kinase } \\
\text { substrate } 1\end{array}$ & NUCKS1, JC7 & DNA binding & $\begin{array}{l}\text { DNA damage response, homolo- } \\
\text { gous recomb. }\end{array}$ & NUCKS1 \\
\hline NUF2, NDC80 kinetochore complex component & NUF2, CDCA1 & Complex formation & $\begin{array}{l}\text { Chromosome segregation, micro- } \\
\text { tubule binding }\end{array}$ & NUF2 \\
\hline NUP107, nucleoporin 107 & NUP107 & Complex formation & Nucleocytoplasmic transport & NUP107 \\
\hline NUP205, nucleoporin 205 & NUP205 & Complex formation & Nucleocytoplasmic transport & NUP205 \\
\hline NUP35, nucleoporin 35 & $\begin{array}{l}\text { NUP35, } \\
\text { NUP53 }\end{array}$ & Complex formation & Nucleocytoplasmic transport & NUP35 \\
\hline NUP85, nucleoporin 85, Pericentrin-1 & NUP85 & Complex formation & Nucleocytoplasmic transport & NUP85 \\
\hline $\begin{array}{l}\text { NUSAP1, nucleolar and spindle associated protein } \\
1\end{array}$ & $\begin{array}{l}\text { NUSAP1, } \\
\text { SAPL }\end{array}$ & Complex formation & Mitotic spindle microtubules & NUSAP1 \\
\hline $\begin{array}{l}\text { OCT1, POU class } 2 \text { homeobox } 1 \text {, Octamer-binding } \\
\text { protein } 1\end{array}$ & $\begin{array}{l}\text { OCT1, } \\
\text { POU2F1 }\end{array}$ & Transcription factor & Proliferation, immune modulation & POU2F1 \\
\hline OIP5, Opa interacting protein 5 & OIP5 & Complex formation & $\begin{array}{l}\text { Centromere binding, chromosome } \\
\text { segregation }\end{array}$ & OIP5 \\
\hline ORC1, origin recognition complex subunit 1 & ORC1 & DNA binding & DNA replication & ORC1 \\
\hline PALB2, partner and localizer of BRCA2 & $\begin{array}{l}\text { PALB2, } \\
\text { FANCN }\end{array}$ & $\begin{array}{l}\text { Complex form., DNA } \\
\text { bindg. }\end{array}$ & $\begin{array}{l}\text { Fanconi anemia, DNA repair, } \\
\text { replication }\end{array}$ & $\begin{array}{l}\text { PALB2, } \\
\text { FANCN }\end{array}$ \\
\hline CENP-M, Centromere protein M & $\begin{array}{l}\text { PANE1, } \\
\text { CENP-M }\end{array}$ & Complex formation & Kinetochore formation, mitosis & CENPM \\
\hline PARPBP, PARP1 binding protein & PARPBP & Complex formation & DNA repair, genomic stability & PARPBP \\
\hline pericentrin & Pericentrin & Complex formation & $\begin{array}{l}\text { Centrosome, microtubules, cilia } \\
\text { assembly }\end{array}$ & PCNT \\
\hline PHF19, PHD finger protein 19 & PHF19 & Complex formation & & PHF19 \\
\hline
\end{tabular}


Table 1 (Continued)

\begin{tabular}{|c|c|c|c|c|}
\hline \multicolumn{5}{|c|}{ Genes regulated by the p53-DREAM pathway } \\
\hline \multirow[t]{2}{*}{ Protein name } & \multirow[t]{2}{*}{ Protein } & \multirow[t]{2}{*}{$\begin{array}{l}\text { Function, enzymatic } \\
\text { activity }\end{array}$} & GO - Gene Ontology & Gene \\
\hline & & & $\begin{array}{l}\text { Histone binding, transcription, } \\
\text { repression }\end{array}$ & \\
\hline PICH, Plk1-interacting checkpoint helicase & $\begin{array}{l}\mathrm{PICH} \\
\text { ERCC6L }\end{array}$ & DNA helicase & $\begin{array}{l}\text { DNA repair, spindle assembly, } \\
\text { anaphase }\end{array}$ & ERCC6L \\
\hline PIF1, 5'-to-3' DNA helicase & PIF1 & $\begin{array}{l}\text { ATPase, DNA } \\
\text { helicase }\end{array}$ & DNA repair, telomere maintenance & PIF1 \\
\hline PLK1, Polo-like kinase 1 & PLK1 & $\begin{array}{l}\text { Serine/threonine } \\
\text { kinase }\end{array}$ & G2/M transition, mitosis & PLK1 \\
\hline PLK4, Polo-like kinase 4 & PLK4 & $\begin{array}{l}\text { Serine/threonine } \\
\text { kinase }\end{array}$ & G2/M transition, mitosis & PLK4, SAK \\
\hline POC5, centriolar protein & POC5 & & Centriole elongation & POC5 \\
\hline POLA1, DNA polymerase alpha-1, catalytic subunit & POLA1 & DNA polymerase & DNA replication & POLA1 \\
\hline POLD1, DNA polymerase delta 1 , catalytic subunit & POLD1 & $\begin{array}{l}\text { DNA polymerase, } \\
\text { exonucl. }\end{array}$ & DNA replication, DNA repair & POLD1 \\
\hline $\begin{array}{l}\text { POLD3, DNA polymerase delta 3, accessory } \\
\text { subunit }\end{array}$ & POLD3 & $\begin{array}{l}\text { DNA polymerase, } \\
\text { exonucl. }\end{array}$ & $\begin{array}{l}\text { DNA replication, DNA repair, mis- } \\
\text { match repair }\end{array}$ & POLD3 \\
\hline POLE, DNA polymerase epsilon, catalytic subunit & POLE & DNA polymerase & DNA replication, DNA repair & POLE \\
\hline POLQ, DNA polymerase theta & POLQ & DNA polymerase & DNA replication, DNA repair & POLQ \\
\hline POP7 homolog, ribonuclease P/MRP subunit & POP7 & Ribonuclease & tRNA processing & POP7 \\
\hline $\mathrm{PPIH}$, peptidylprolyl isomerase $\mathrm{H}$ & $\mathrm{PPIH}$ & $\begin{array}{l}\text { Peptidylprolyl } \\
\text { isomerase }\end{array}$ & Protein folding, mRNA splicing & PPIH \\
\hline PRC1, protein regulator of cytokinesis 1 & PRC1 & Complex formation & $\begin{array}{l}\text { Cytokinesis, spindle formation, } \\
\text { mitosis }\end{array}$ & PRC1 \\
\hline PRIM1, primase (DNA) subunit 1 & PRIM1 & $\begin{array}{l}\text { DNA primase, RNA } \\
\text { synthesis }\end{array}$ & DNA replication & PRIM1 \\
\hline PRIM2, primase (DNA) subunit 2 & PRIM2 & DNA primase & $\begin{array}{l}\text { DNA replication, telomere } \\
\text { maintenance }\end{array}$ & PRIM2 \\
\hline PRR11, proline rich 11 & PRR11 & & Cell cycle regulation & PRR11 \\
\hline $\begin{array}{l}\text { Partner of SLD Five 1, DNA replication complex } \\
\text { GINS protein PSF1 }\end{array}$ & PSF1, GINS1 & DNA helicase & DNA helicase, replication & GINS1 \\
\hline $\begin{array}{l}\text { Partner of SLD Five 2, DNA replication complex } \\
\text { GINS protein PSF2 }\end{array}$ & PSF2, GINS2 & Complex formation & DNA helicase, replication & GINS2 \\
\hline PSRC1, proline and serine rich coiled-coil 1 & PSRC1, DDA3 & Complex formation & Microtubule polymerization, mitosis & PSRC1 \\
\hline Securin, PTTG1, pituitary tumor-transforming 1 & $\begin{array}{l}\text { PTTG1, } \\
\text { securin }\end{array}$ & Complex formation & $\begin{array}{l}\text { Mitotic spindle assembly check- } \\
\text { point, mitosis }\end{array}$ & PTTG1 \\
\hline RACGAP1, Rac GTPase-activating protein 1 & RACGAP1 & $\begin{array}{l}\text { Regulation of small } \\
\text { GTPase }\end{array}$ & Cytokinesis, mitosis & RACGAP1 \\
\hline RAD18, E3 ubiquitin protein ligase & RAD18 & Ubiquitin ligase & $\begin{array}{l}\text { Detection of DNA damage, DNA } \\
\text { repair }\end{array}$ & RAD18 \\
\hline RAD21, cohesin complex component & RAD21 & Complex formation & $\begin{array}{l}\text { Chromosome cohesion, DNA } \\
\text { repair, apoptosis }\end{array}$ & RAD21 \\
\hline RAD51, recombinase & $\begin{array}{l}\text { RAD51, } \\
\text { FANCR }\end{array}$ & $\begin{array}{l}\text { DNA-dependent } \\
\text { ATPase }\end{array}$ & Fanconi anemia, DNA repair & $\begin{array}{l}\text { RAD51, } \\
\text { FANCR }\end{array}$ \\
\hline RAD54-like & RAD54L & DNA helicase & DNA repair, mitotic recombination & RAD54L \\
\hline RANGAP1, Ran GTPase-activating protein 1 & RANGAP1 & $\begin{array}{l}\text { Ran GTPase activa- } \\
\text { tor activity }\end{array}$ & $\begin{array}{l}\text { Nuclear pore complex, kinetochore, } \\
\text { mitosis }\end{array}$ & RANGAP1 \\
\hline RECQL4, RecQ like helicase 4 & RECQL4 & $\begin{array}{l}\text { DNA helicase, } \\
\text { ATPase }\end{array}$ & $\begin{array}{l}\text { DNA repair, replication, } \\
\text { recombination }\end{array}$ & RECQL4 \\
\hline REEP4, receptor accessory protein 4 & REEP4 & Complex formation & $\begin{array}{l}\text { Microtubule bdg, nuclear envelope } \\
\text { reassembly }\end{array}$ & REEP4 \\
\hline $\begin{array}{l}\text { RHINO, RAD9-HUS1-RAD1 interacting nuclear } \\
\text { orphan } 1\end{array}$ & RHINO & Complex formation & $\begin{array}{l}\text { DNA repair, cellular response to } \\
\text { DNA damage }\end{array}$ & $\begin{array}{l}\text { RHNO1, } \\
\text { C12orf32 }\end{array}$ \\
\hline RIF1, replication timing regulatory factor 1 & RIF1 & Complex formation & $\begin{array}{l}\text { DNA repair, checkpoint control, } \\
\text { telemore bindg. }\end{array}$ & RIF1 \\
\hline RNASEH2A, ribonuclease $\mathrm{H} 2$ subunit $A$ & RNASEH2A & RNA endonuclease & DNA replication & RNASEH2A \\
\hline RNF26, ring finger protein 26 & RNF26 & Ubiquitin ligase & $\begin{array}{l}\text { Endosomal maturation and } \\
\text { trafficking }\end{array}$ & RNF26 \\
\hline RPA2, replication protein A2 & RPA2 & $\begin{array}{l}\text { Complex form., DNA } \\
\text { bindg. }\end{array}$ & DNA repair, replication & RPA2 \\
\hline RTKN2, rhotekin 2 & RTKN2 & Rho GTPase effector & Cell cycle regulation, apoptosis & RTKN2 \\
\hline $\begin{array}{l}\text { SAS- } 6 \text { centriolar assembly protein, Spindle assem. } \\
\text { abn. protein } 6\end{array}$ & SAS6, SASS6 & Complex formation & $\begin{array}{l}\text { Centrosome duplication, procen- } \\
\text { triole formation }\end{array}$ & SASS6 \\
\hline SCLT1, sodium channel and clathrin linker 1 & SCLT1 & Complex formation & Clathrin binding, cilia assembly & SCLT1 \\
\hline Separase, extra spindle pole bodies like 1 & $\begin{array}{l}\text { Separase, } \\
\text { ESPL1 }\end{array}$ & Protease & Chromosome segregation & ESPL1 \\
\hline SETD8, lysine methyltransferase 5A & $\begin{array}{l}\text { SETD8, } \\
\text { KMT5A }\end{array}$ & $\begin{array}{l}\text { Lysine } N \text { - } \\
\text { methyltransferase }\end{array}$ & $\begin{array}{l}\text { Protein methylation, transcriptional } \\
\text { repression }\end{array}$ & $\begin{array}{l}\text { KMT5A, } \\
\text { SETD8 }\end{array}$ \\
\hline SGO1, shugoshin 1 & SGO1, SGOL1 & Complex formation & $\begin{array}{l}\text { Chromosome segregation, centro- } \\
\text { mere binding }\end{array}$ & $\begin{array}{l}\text { SGOL1, } \\
\text { SGO1 }\end{array}$ \\
\hline SGO2, shugoshin 2 & SGO2, SGOL2 & Complex formation & & \\
\hline
\end{tabular}


Table 1 (Continued)

\begin{tabular}{|c|c|c|c|c|}
\hline \multicolumn{5}{|c|}{ Genes regulated by the p53-DREAM pathway } \\
\hline Protein name & Protein & $\begin{array}{l}\text { Function, enzymatic } \\
\text { activity }\end{array}$ & GO - Gene Ontology & Gene \\
\hline & & & $\begin{array}{l}\text { Sister chromatid cohesion, meiosis, } \\
\text { centromere }\end{array}$ & $\begin{array}{l}\text { SGOL2, } \\
\text { SGO2 }\end{array}$ \\
\hline SHCBP1, SHC binding and spindle associated 1 & SHCBP1 & & Cell proliferation & SHCBP1 \\
\hline $\begin{array}{l}\text { SKA1, Spindle and kinetochore-associated protein } \\
1\end{array}$ & SKA1 & Complex formation & Kinetochore, microtubules, mitosis & SKA1 \\
\hline $\begin{array}{l}\text { SKAP, kinetochore localized astrin/SPAG5 binding } \\
\text { protein }\end{array}$ & $\begin{array}{l}\text { SKAP, } \\
\text { KNSTRN }\end{array}$ & Complex formation & $\begin{array}{l}\text { Mitotic spindle, chromosome } \\
\text { segregation }\end{array}$ & KNSTRN \\
\hline SKP2, S-phase kinase associated protein 2 & SKP2 & F-box-like protein & Protein ubiquitination & SKP2 \\
\hline SLC25A40, solute carrier family 25 member 40 & SLC25A40 & & Mitochondrial carrier & SLC25A40 \\
\hline SMC-2, structural maintenance of chromosomes 2 & SMC-2 & ATP binding & DNA condensation, mitosis & SMC2 \\
\hline SMC-4, structural maintenance of chromosomes 4 & SMC-4 & ATP binding & DNA condensation, mitosis & SMC4 \\
\hline $\begin{array}{l}\text { structural maintenance of chromos. Flex. hinge } \\
\text { domain contain. } 1\end{array}$ & SMCHD1 & Complex formation & DNA methylation & SMCHD1 \\
\hline Sororin, CDCA5 & $\begin{array}{l}\text { Sororin, } \\
\text { CDCA5 }\end{array}$ & Chromatin binding & Mitotic sister chromatid cohesion & $\begin{array}{l}\text { CDCA5, } \\
\text { Sororin }\end{array}$ \\
\hline Sp4, transcription factor & SP4 & Transcription factor & Transcription & SP4 \\
\hline SPAG5, sperm associated antigen 5 & SPAG5 & Complex formation & $\begin{array}{l}\text { Mitotic spindle, chromosome } \\
\text { segregation }\end{array}$ & SPAG5 \\
\hline SPC25, NDC80 kinetochore complex component & SPC25 & Complex formation & $\begin{array}{l}\text { Chromosome segregation, micro- } \\
\text { tubule binding }\end{array}$ & SPC25 \\
\hline Spindly, Coiled-coil domain-containing protein 99 & $\begin{array}{l}\text { SPDL1/ } \\
\text { CCDC99 }\end{array}$ & Kinetochore binding & $\begin{array}{l}\text { Establishment of mitotic spindle } \\
\text { orientation }\end{array}$ & $\begin{array}{l}\text { SPDL1/ } \\
\text { CCDC99 }\end{array}$ \\
\hline STIL, SCL/TAL1 interrupting locus & STIL & & $\begin{array}{l}\text { Embryonic development, cell } \\
\text { proliferation }\end{array}$ & STIL \\
\hline $\begin{array}{l}\text { STK17B, serine/threonine kinase 17b (apoptosis- } \\
\text { inducing) }\end{array}$ & $\begin{array}{l}\text { STK17B, } \\
\text { DRAK2 }\end{array}$ & $\begin{array}{l}\text { Serine/threonine } \\
\text { kinase }\end{array}$ & Apoptosis & $\begin{array}{l}\text { STK17B, } \\
\text { DRAK2 }\end{array}$ \\
\hline Survivin, baculoviral IAP repeat containing 5 & $\begin{array}{l}\text { Survivin, } \\
\text { BIRC5 }\end{array}$ & $\begin{array}{l}\text { Chromosomal pass. } \\
\text { complex }\end{array}$ & Mitosis, cytokinesis, transcription & BIRC5 \\
\hline SUZ12, polycomb repressive complex 2 subunit & SUZ12 & Complex formation & $\begin{array}{l}\text { Transcriptional repession, histone } \\
\text { methylation }\end{array}$ & SUZ12 \\
\hline $\begin{array}{l}\text { TACC } 3 \text {, transforming acidic coiled-coil containing } \\
\text { protein } 3\end{array}$ & TACC3, ERIC1 & Complex formation & $\begin{array}{l}\text { Spindle/microtubule formation, } \\
\text { mitosis }\end{array}$ & TACC3 \\
\hline Tastin, Trophinin-assisting protein, TROAP & Tastin, TROAP & Complex formation & Cell adhesion & $\begin{array}{l}\text { Tastin, } \\
\text { TROAP }\end{array}$ \\
\hline TCERG1, transcription elongation regulator 1 & $\begin{array}{l}\text { TCERG1, } \\
\text { CA150 }\end{array}$ & Transcription factor & Inhibition of transcript elongation & TCERG1 \\
\hline TIMELESS, timeless circadian clock & $\begin{array}{l}\text { TIMELESS, } \\
\text { TIM1 }\end{array}$ & Complex formation & $\begin{array}{l}\text { Circadian rhythm, DNA repair, } \\
\text { replication }\end{array}$ & TIMELESS \\
\hline Thymidine kinase 1 & TK1 & Kinase & DNA synthesis & TK1 \\
\hline $\begin{array}{l}\text { Thymopoietin, Lamina-associated polypeptide } 2 \text {, } \\
\text { isoform alpha }\end{array}$ & TMPO, LAP2 & Complex formation & $\begin{array}{l}\text { Nuclear structure, post-mitotic } \\
\text { nuclear assembly }\end{array}$ & TMPO, LAP2 \\
\hline TOP2A, topoisomerase (DNA) II alpha & TOP2A & DNA topoisomerase & $\begin{array}{l}\text { Mitosis, meiosis, chromosome } \\
\text { segregation }\end{array}$ & TOP2A \\
\hline TPX2, microtubule nucleation factor & TPX2 & Complex formation & $\begin{array}{l}\text { Mitotic spindle assembly, apoptosis, } \\
\text { G2/M trans }\end{array}$ & TPX2 \\
\hline TRAIP, TRAF interacting protein, TRIP & TRAIP, TRIP & Ubiquitin ligase & $\begin{array}{l}\text { Signal transduction, apoptosis, } \\
\text { spindle, mitosis }\end{array}$ & TRAIP, TRIP \\
\hline $\begin{array}{l}\text { Treslin, TOPBP1 interacting checkpoint and repli- } \\
\text { cation regulator }\end{array}$ & Treslin, SLD3 & Complex formation & $\begin{array}{l}\text { DNA replication, DNA repair, } \\
\text { checkpoint control }\end{array}$ & $\begin{array}{l}\text { TICRR, } \\
\text { Treslin }\end{array}$ \\
\hline $\begin{array}{l}\text { TTK, Mitotic checkpoint kinase Mps1, TTK protein } \\
\text { kinase }\end{array}$ & TTK, MPS1 & $\begin{array}{l}\text { Serine/threonine/tyr. } \\
\text { kinase }\end{array}$ & Spindle formation, mitosis & TTK, MPS1 \\
\hline $\begin{array}{l}\text { SNRPA, small nuclear ribonucleoprotein polypep- } \\
\text { tide A }\end{array}$ & U1A, SNRPA & Complex formation & U1 snRNA binding, splicing & SNRPA, U1A \\
\hline $\begin{array}{l}\text { UACA, Uveal autoantigen with coiled-coil domains } \\
\text { and ankyrin repeats }\end{array}$ & UACA & Complex formation & Apoptosis & UACA \\
\hline $\begin{array}{l}\text { UBE2C, Ubiquitin-conjugating enzyme E2 C, } \\
\text { UbcH10 }\end{array}$ & $\begin{array}{l}\text { UBE2C, } \\
\text { UbcH10 }\end{array}$ & $\begin{array}{l}\text { Ubiquitin conjug. } \\
\text { enzyme }\end{array}$ & Mitosis & $\begin{array}{l}\text { UBE2C, } \\
\text { UbcH10 }\end{array}$ \\
\hline UBE2S, Ubiquitin-conjugating enzyme E2 S & UBE2S & $\begin{array}{l}\text { Ubiquitin conjug. } \\
\text { enzyme }\end{array}$ & Exit from mitosis & UBE2S \\
\hline UBE2T, Ubiquitin-conjugating enzyme E2 T & $\begin{array}{l}\text { UBE2T, } \\
\text { FANCT }\end{array}$ & $\begin{array}{l}\text { Ubiquitin conjug. } \\
\text { enzyme }\end{array}$ & $\begin{array}{l}\text { Fanconi anemia, DNA repair, } \\
\text { ubiquitination }\end{array}$ & $\begin{array}{l}\text { UBE2T, } \\
\text { FANCT }\end{array}$ \\
\hline UDG, uracil DNA glycosylase & UDG, UNG & $\begin{array}{l}\text { Uracil DNA } N- \\
\text { glycosylase }\end{array}$ & DNA repair, base-excision repair & UNG \\
\hline USP1, ubiquitin specific peptidase 1 & USP1, UBP & Endopeptidase & $\begin{array}{l}\text { De-ubiquitination, neg. regulation } \\
\text { DNA repair }\end{array}$ & USP1 \\
\hline Wee1-like protein kinase & WEE1 & $\begin{array}{l}\text { Serine/threonine } \\
\text { kinase }\end{array}$ & G2/M transition, mitosis & WEE1 \\
\hline $\begin{array}{l}\text { WD repeat containing antisense to TP53, Telomer- } \\
\text { ase Cajal body pr. }\end{array}$ & $\begin{array}{l}\text { WRAP53, } \\
\text { TCAB1 }\end{array}$ & $\begin{array}{l}\text { Telomerase } \\
\text { component }\end{array}$ & $\begin{array}{l}\text { Telomere maintenance, p53 anti- } \\
\text { sense transcript }\end{array}$ & WRAP53 \\
\hline
\end{tabular}


Table 1 (Continued)

\begin{tabular}{|c|c|c|c|c|}
\hline \multicolumn{5}{|c|}{ Genes regulated by the p53-DREAM pathway } \\
\hline Protein name & Protein & $\begin{array}{c}\text { Function, enzymatic } \\
\text { activity }\end{array}$ & GO - Gene Ontology & Gene \\
\hline $\begin{array}{l}\text { YEATS4, YEATS domain-containing } 4 \\
\text { ZNF367, zinc-finger protein 367, CDC14B } \\
\text { ZRANB3, zinc-finger, RAN-binding domain-con- } \\
\text { taining } 3\end{array}$ & $\begin{array}{l}\text { YEATS4, } \\
\text { GAS41 } \\
\text { ZNF367 } \\
\text { ZRANB3, AH2 }\end{array}$ & $\begin{array}{l}\text { Complex formation } \\
\text { DNA binding } \\
\text { Helicase and } \\
\text { endonuclease }\end{array}$ & $\begin{array}{l}\text { Transcription, histone acetylation } \\
\text { Transcription } \\
\text { DNA repair, cellular response to } \\
\text { DNA damage }\end{array}$ & $\begin{array}{l}\text { YEATS4, } \\
\text { GAS41 } \\
\text { ZNF367 } \\
\text { ZRANB3, } \\
\text { AH2 }\end{array}$ \\
\hline
\end{tabular}

Genes listed bind DREAM components in their promoters and are downregulated following p53 activation. The list was compiled from meta-analyses reported in several studies. ${ }^{17,29,31,66}$ Criteria for inclusion as genes regulated by the p53-p21-DREAM-E2F/CHR (p53-DREAM) pathway are binding of p130, E2F4, LIN9, LIN54, and the lack of binding by $\mathrm{p} 53$ as assayed by ChIP together with downregulation of target gene mRNA after activation of p53. ${ }^{17,29,31,66}$ An updated compilation of data sets from several genome-wide studies has been published ${ }^{65,67}$ and can be consulted to retrieve data on individual genes at www.targetgenereg.org.

Cellular functions of the p53-p21-DREAM-E2F/CHR pathway

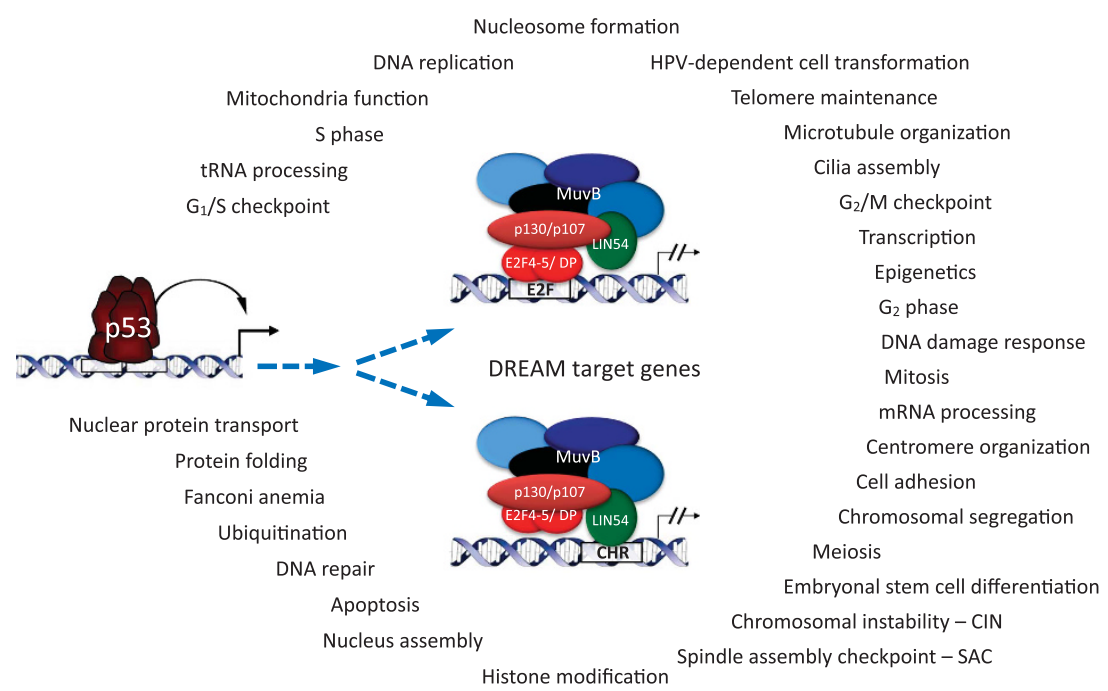

Figure 4 Cellular functions of the p53-p21-DREAM-E2F/CHR pathway. In order to summarize cellular functions regulated by the pathway, gene ontology terms for p53-p21-DREAM-E2F/CHR targets from Table 1 were compiled

DHFR are now considered p53-DREAM targets ${ }^{77,78}$ (Table 1). The E2F or E2F/CLE sites in their promoters are bound by DREAM for repression in resting cells and the E2F elements may bind activating E2F complexes at later stages of the cell cycle $^{33}$ (Figure 1).

\section{p53-Repressed Genes Required for the $G_{2}$ Phase and Mitosis are Controlled by CHR Elements}

In addition to controlling the $\mathrm{G}_{1} / \mathrm{S}$ checkpoint, p53 also has a role in regulating genes required for progression through $G_{2}$ phase and mitosis. ${ }^{30,66,79}$ Cell cycle-dependent expression of these genes is controlled by CHR or CDE/CHR sites in their promoters $^{31,33}$ (Figure 1). Prominent examples for p53DREAM-regulated genes involved in $\mathrm{G}_{2} / \mathrm{M}$ checkpoint control and progression through mitosis are CHEK2, CDK1, CCNB1, CCNB2 and CDC25C $C^{10,14,31,39,66,80,81}$ (Table 1).

In addition to such central regulators, also genes coding for proteins required in the mechanical execution of mitosis are controlled by the p53-DREAM pathway, such as kinesins. ${ }^{82}$
Of the many kinesins discovered in bioinformatic screens as p53-DREAM targets, KIF2C, KIF23 and KIF24 have been studied in detail and were validated to be controlled by DREAM $^{29,31,68,83}$ (Table 1).

\section{The p53-DREAM Pathway and its Role in the Spindle Assembly Checkpoint, Chromosomal Instability, Aneuploidy in Cancer Cells and Mitotic Catastrophe}

Several gene products mentioned above together with many additional cell cycle proteins are required for accurate segregation of chromosomes. Deregulation of their genes can perturb the spindle assembly checkpoint and lead to chromosomal instability (CIN). ${ }^{84-87} \mathrm{CIN}$ and resulting aneuploidy are considered hallmarks of cancer cells. Deregulated expression of mitosis genes has been shown in numerous studies to cause aneuploidy and tumor development. ${ }^{88}$ Importantly, many genes involved in chromosome segregation are p53-DREAM targets (Table 1). Similarly, several genes important for mitosis which are downregulated by the p53- 
DREAM pathway are part of the DNA damage response. Repression of these genes leads to perturbations in the mitotic machinery. As a consequence of depriving cells of these regulators, cells can arrest in mitosis and undergo the death program of mitotic catastrophe. ${ }^{89}$

As chromosomal missegregation causes elevated levels of p53 and p21/CDKN1A, ${ }^{90}$ the p53-DREAM pathway becomes activated and many genes required for segregation of chromosomes are downregulated (Table 1). The lack of expression of segregation regulators results in cell cycle arrest. In cells that have lost p53 or p21/CDKN1A function, the ability to arrest the cell cycle is compromised causing CIN and aneuploidy. ${ }^{90}$

Numerous gene products involved in mitotic spindle formation, kinetochore function, microtubule binding, centromere organization and centrosome formation such as CENPA/C/E/F/L/N/O/W, CAF1A, MCM2-8, INCENP and CEP152/295 are implicated as p53-DREAM targets (Table 1). Furthermore, several genes involved in these processes BIRC5 (Survivin), CEP55, PLK1, GAS2L3 and PRC1 - have been established as DREAM targets in detailed experimental studies. ${ }^{19,91-93}$

As two examples, the histone H3-like CENP-A protein $(\mathrm{CenH} 3)$ and its chaperone HJURP (Holliday junction recognition protein) have important functions in centromere formation. Their expression peaks in the $G_{2}$ phase. CENP-A is incorporated into centromeric chromatin between telophase and early $\mathrm{G}_{1}$ to form centromere-specific nucleosomes and to facilitate kinetochore binding to the centromere. ${ }^{94}$ CENPA and HJURP genes had been predicted as targets repressed by the p53-DREAM pathway. ${ }^{66}$ Recently, it has been confirmed that these two factors are indeed downregulated indirectly by p53 requiring $\mathrm{CDE} / \mathrm{CHR}$ sites in their promoters and a functional p21/CDKN1A CDK inhibitor. ${ }^{95}$ Consistently, expression of CENPA and HJURP mRNA was found increased in several tumor types which lack functional p53 compared with samples with wild-type p53. Notably, the report suggests that overexpression of CENPA and HJURP is not simply a consequence but may be one of the causes of cell cycle deregulation after p53 inactivation and cellular transformation. This assumption stems from the observation that mRNA levels of the $\mathrm{G}_{2} / \mathrm{M}$ genes CENPA and HJURP remain high even when a decreasing proportion of cells enters $\mathrm{G}_{2} / \mathrm{M}$ and an increasing proportion of cells undergoes apoptosis. ${ }^{95}$

Also in the context of preventing supernumerary centrosomes, the formation of the PIDDosome from its components together with its regulatory effect on p53 displays a balancing network of feedback loops. The PIDDosome via Caspase-2 mediates MDM2 cleavage leading to p53 stabilization and p21/CDKN1A activation. ${ }^{96}$ While expression of the PIDDosome constituent $P I D D 1$ is strongly induced, expression of another component, CRADD (RAIDD), is not significantly affected by p53. ${ }^{17}$ In contrast, the CASP2 (Caspase-2) component is clearly downregulated, possibly via p53DREAM. $^{17}$

Furthermore, it has been shown that loss of p53 causes centrosome amplification. ${ }^{97}$ Particularly overexpression of cell cycle regulators such as PLK4, which is also downregulated by the p53-DREAM pathway, was reported to be central to the amplification of centrosomes. ${ }^{69,98}$ More importantly, overexpression of these genes was implicated not as a consequence but rather as a cause contributing to the formation of tumors ${ }^{92,98}$

As a result, deregulation of p53 cell cycle targets leads to centrosome amplification which promotes aneuploidy and ultimately tumorigenesis. ${ }^{98}$ In general, these observations suggest a tumor-suppressive function of the p53-DREAM pathway.

\section{Entire functional Groups of Genes are Downregulated by the p53-DREAM Pathway: DNA Repair, Telomere Maintenance and Fanconi Anemia}

Bioinformatic analysis of mRNA expression, ChIP and promoter element conservation data pointed at several genes involved in DNA repair and telomere maintenance to be downregulated by the DREAM pathway. ${ }^{17}$ Among the genes suggested to be regulated by DREAM were examples such as FANCB, DCLRE1B (Apollo), RAD54L, RAD18 and CHEK2 $2^{17,31,66}$ (Table 1). Interestingly, some of the DREAM targets are genes of the Fanconi anemia complementation groups (Table 2). ${ }^{17,99}$

Fanconi anemia is the most common inherited bone marrow failure syndrome. It causes constitutive genomic instability and predisposes for myelodysplasia, myeloid leukemia and solid tumors such as squamous cell carcinomas. ${ }^{100}$ Recently, expression of Fanconi anemia genes in the context of truncated vs full-length p53 was investigated in a mouse model. A truncated variant of p53 missing the C-terminal 31 amino acids was employed and its transcriptional program in comparison with full-length p53 was tested. ${ }^{101}$ The p53 $\Delta 31$ mutant lacks the $\mathrm{C}$-terminal domain which interferes with DNA binding reducing p53 activity. ${ }^{102}$ Thus, p53 $\Delta 31$ displays elevated transcriptional activity compared with full-length p53 resulting in enhanced p21/CDKN1A activation and concomitant induction of the p53-DREAM pathway. ${ }^{39,101}$ It was shown that several Fanconi anemia genes are repressed by $\mathrm{p} 53$, bind E2F4 after induction of $\mathrm{p} 53$ and contain candidate $\mathrm{CDE} / \mathrm{CHR}$ sites in their promoters (Table 2). Detailed analyses were performed with FANCD2, FANCI and RAD51 (FANCR) by testing mutants of CDE/CHR sites in their promoters. ${ }^{101}$ Consistently, all Fanconi anemia genes which were experimentally confirmed to be controlled through DREAM had also been predicted by bioinformatic analyses as DREAM targets $^{17,101}$ (Table 2). These data suggest that an entire group of functionally related genes is coordinately downregulated by the p53-DREAM pathway. The coordinate regulation of whole functional groups implies that the p53DREAM pathway controls not just a partial aspect but an entire function of a cell (Figure 4).

Another group of genes associated with telomere maintenance partially overlaps with the Fanconi anemia gene family as some genes from both groups are involved in DNA repair. ${ }^{101}$ The telomere-related DKC1 (Dyskerin), RTEL1 and TINF2 genes are found mutated in dyskeratosis congenita. From the meta-analysis data it is unclear whether they are also DREAM targets ${ }^{17,101}$ (Table 2). However, many genes with functions in telomere maintenance, length or replication as well as DNA repair - e.g. DEK, FEN1, RECQL4, TIMELESS, BLM, RIF1, ACD, RPA2, WRAP53 (TCAB1), TRAIP and PIF1 
Table 2 DREAM targets among Fanconi anemia, dyskeratosis congenita, and related DNA repair and telomere maintenance genes

\begin{tabular}{|c|c|c|c|}
\hline \multirow[t]{2}{*}{ Gene name } & \multirow{2}{*}{$\begin{array}{l}\frac{\text { Fanconi }}{\text { Complementation }} \\
\text { Group or DC }\end{array}$} & \multirow{2}{*}{$\begin{array}{l}\text { DREAM pathway } \\
\text { Target } \\
\text { Fischer et al. }{ }^{17}\end{array}$} & \multirow{2}{*}{$\begin{array}{l}\text { Repressed by p53 } \\
{\text { Jaber et } \text { al. }^{101}}^{10}\end{array}$} \\
\hline & & & \\
\hline BLM & & $\checkmark$ & $\checkmark$ \\
\hline BRCA1 & FANCS & 2 & $\checkmark$ \\
\hline BRCA2 & FANCD1 & $\checkmark$ & 2 \\
\hline BRIP1 (BACH1) & FANCJ & $\checkmark$ & $\checkmark$ \\
\hline DCLRE1B (Apollo) & & $\checkmark$ & \\
\hline DEK & & $\checkmark$ & $\checkmark$ \\
\hline $\begin{array}{l}\text { DKC1 (Dyskerin) } \\
\text { ERCC4 (XPF, RAD1) }\end{array}$ & $\begin{array}{l}\text { Dyskeratosis Congen. } \\
\text { FANCQ }\end{array}$ & $\begin{array}{l}\text { unclear } \\
\text { no }\end{array}$ & \\
\hline FANCA & FANCA & $\checkmark$ & $\checkmark$ \\
\hline FANCB & FANCB & 2 & 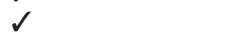 \\
\hline FANCC & FANCC & $\checkmark$ & \\
\hline FANCD2 & FANCD2 & $\checkmark$ & $\checkmark$ \\
\hline FANCE & FANCE & $\checkmark$ & \\
\hline FANCF & FANCF & no & \\
\hline FANCG & FANCG & $\checkmark$ & \\
\hline FANCl & FANCl & $\checkmark$ & $\checkmark$ \\
\hline FANCL & FANCL & $\checkmark$ & \\
\hline FANCM & FANCM & $\checkmark$ & $\checkmark$ \\
\hline FEN1 & & $d$ & $\checkmark$ \\
\hline GAR1 & & unclear & $\checkmark$ \\
\hline PALB2 & FANCN & $\checkmark$ & $\checkmark$ \\
\hline RAD51 & FANCR & 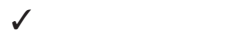 & $\checkmark$ \\
\hline RAD51C & FANCO & unclear & 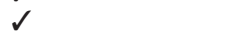 \\
\hline RECQL4 & & $\checkmark$ & $\checkmark$ \\
\hline RTEL1 & Dyskeratosis Congen. & unclear & \\
\hline SLX4 (BTBD12) & FÁNCP & no & \\
\hline Timeless & & $\checkmark$ & $\checkmark$ \\
\hline TINF2 (TIN2) & Dyskeratosis Congen. & no & \\
\hline UBE2T & FANCT & $\checkmark$ & $\checkmark$ \\
\hline ACD & & $\checkmark$ & \\
\hline RIF1 & & $\checkmark$ & \\
\hline PIF1 (RRM3) & & $\checkmark$ & \\
\hline RPA2 & & $\checkmark$ & \\
\hline TRAIP & & $\checkmark$ & \\
\hline WRAP53 (TCAB1) & & $\checkmark$ & \\
\hline
\end{tabular}

Abbreviation: DC, dyskeratosis congenita

To assess whether genes related to DNA repair, telomere maintenance ${ }^{103,124}$ and Fanconi anemia ${ }^{99,100,105}$ are DREAM targets, data on mRNA regulation after p53 activation and binding of DREAM components E2F4, p130, LIN9 and LIN54 were retrieved from a database by Fischer et al. ${ }^{17}$ An updated data compilation can be accessed at www.targetgenereg.org. ${ }^{65}$ Jaber et al. ${ }^{101}$ have recently confirmed that p53 downregulates many of the Fanconi anemia genes by DREAM binding to CDE/ CHR sites.

(RRM3) - are indirectly downregulated by p53. Correspondingly, binding of DREAM components to these genes was observed by genome-wide ChIP experiments, again indicating that a functionally related gene set is controlled by the p53DREAM pathway ${ }^{17,101,103,104}$ (Table 2).

Also breast and ovarian cancer susceptibility genes BRCA1 and $B R C A 2$ are among the genes implied as DREAM targets by observations from several genome-wide screens. ${ }^{17}$ $B R C A 1$ and BRCA2 were originally described as Fanconi complementation groups FANCS and FANCD1, respectively. $^{100}$ This identity has been challenged recently. ${ }^{105}$ Yet, downregulation of these genes by p53 and binding of DREAM components has been shown in a compilation of genome-wide expression and ChIP protein binding data. ${ }^{17}$ Furthermore, before the discovery of mammalian DREAM, observations suggested that E2F4, p130 and p107 can bind at the BRCA1 promoter after induction of hypoxia. ${ }^{106}$ p53-dependent repression of $B R C A 1$ and binding of E2F4 to the gene was later confirmed. ${ }^{107}$

In general, these data suggest that gene groups representing pathways controlling important cell functions such as cell cycle checkpoint regulation, DNA repair, telomere maintenance and other functions are coordinately regulated by the p53-DREAM pathway (Figure 4). Again, this implies that p53 employs DREAM to exert its master regulator function by controlling entire sets of genes responsible for complete cell functions.

\section{Cancer treatment: CDK Inhibitor Drugs and Rescue of the p53-DREAM Pathway}

Cell cycle checkpoint control is in the focus of cancer treatment. Prominent examples for drugs targeting the cell cycle are Palbociclib (PD-0332991, tradename: Ibrance), Abemaciclib (LY2835219) and Ribociclib (LEE 011, Kisqali). ${ }^{108}$ Palbociclib was the first of these small-molecule inhibitors to obtain FDA approval for the treatment of breast cancer. The drugs inhibit CDK4/6 cell cycle kinases and compensate for the loss of checkpoint control in cancerous cells. The CDK inhibitors were originally aimed at primarily decreasing $\mathrm{pRB}$ phosphorylation in order to promote formation $\mathrm{pRB} / \mathrm{E} 2 \mathrm{~F}$ transcriptional repressor complexes. The 
classical view is that hypophosphorylation of $p R B$ is an important step in $\mathrm{G}_{1} / \mathrm{S}$ checkpoint control. ${ }^{58,108}$

However, it has been established early - analogous to pRB itself - that the pRB-related proteins p107 and p130 are substrates for cyclin D/CDK4/6-dependent phosphorylation. ${ }^{109,110}$ Thus, inhibition by drugs such as Palbociclib will lead to DREAM formation and cause downregulation of its target genes. As DREAM controls genes which are required for $G_{1} / S$ transition, the $G_{2} / M$ checkpoint and for progression through mitosis (Table 1), CDK inhibitors such as Palbociclib will address several cell cycle checkpoints by causing DREAM formation. This suggests that the therapeutic effect of the CDK inhibitors may depend on DREAM.

\section{Human Papilloma Virus HPV E7 - Destruction of DREAM Function}

Human papilloma virus (HPV)-16 E7 has been shown to bind the retinoblastoma protein $\mathrm{pRB}$ and impair its tumorsuppressive function. ${ }^{111}$ Consistently, also DREAM was reported to be disrupted by $\mathrm{E} 7$ binding to the pRB-related protein p130. ${ }^{112}$ Moreover, it is established that HPV E6 targets p53 for ubiquitin-mediated destruction. ${ }^{113}$ Also, the HPV E7 protein will compromise the function of p53 as a tumor suppressor through binding to the DREAM components p107 and p130. A genome-wide study listed the genes with their change in expression following HPV E7 protein expression. ${ }^{114}$ In a report on PLK4 transcription, we showed in regard to the mechanism that transcriptional deregulation by HPV E7 is mediated through the DREAM complex and CDE/CHR elements in the promoter of the gene. ${ }^{69}$ In general, these results implied that all genes controlled by DREAM through E2F or CHR sites in their promoters are deregulated by HPV E7. ${ }^{69}$ This notion emerged also from earlier data sets and a recent report on gene deregulation upon E7 expression in keratinocytes. ${ }^{69,114,115}$ In a recent genome-wide meta-analysis we identified more than 90 genes, mostly coding for cell cycle regulators, which are upregulated following E7 expression. ${ }^{116}$ Thus, these data suggest that deregulation of DREAM substantially contributes to HPV E7-mediated tumorigenesis.

\section{DREAM and Epigenetics}

DREAM also regulates genes involved in DNA methylation, nucleosome formation and histone modification, including CHAF1A, EZH2, H2AFX, KMT5A, SMCHD1 and SUZ12 (Table 1). Recently, it was shown that p53-dependent regulation of enzymes is required for DNA methylation homeostasis. ${ }^{117}$ In p53-deficient cells, an imbalance in DNA methylation causes clonal heterogeneity in naïve embryonal stem cells and upon differentiation. The DNA methyltransferase gene DNMT3B contributes to DNA methylation homeostasis and appears to be - according to meta-analysis datadownregulated by the p53-DREAM pathway (Table 1). Thus, with their role in epigenetics, DREAM and the p53-DREAM pathway contribute to gene regulation on a global level.

\section{Implications of the p53-p21-DREAM-E2F/CHR pathway}

p53 is a key mediator of cell cycle arrest in response to cellular stress. With the plethora of genes downregulated by the p53DREAM pathway, it has become likely that this signaling pathway is central to cell cycle arrest (Table 1). Considering that regulator functions of these genes span from the $\mathrm{G}_{1}$ phase to the end of mitosis, it is evident that p53-dependent cell cycle arrest is not restricted to $\mathrm{G}_{1} / \mathrm{S}$ transition but is also important for all checkpoints up to the completion of cell division (Figure 4).

An unresolved issue in cell cycle checkpoint control is how functions of $p R B$ and DREAM differ or overlap. Both $p R B / E 2 F$ complexes and DREAM bind DNA through E2F sites. However, DREAM also employs CHR elements without E2F sites. Thus, gene sets controlled by $\mathrm{pRB} / \mathrm{E} 2 \mathrm{~F}$ or DREAM will overlap but a separate set will be controlled by DREAM and $\mathrm{CHR}$ sites (Figure 2). It has been shown that $\mathrm{pRB}$ and $\mathrm{p} 21 /$ CDKN1A have additive effects on $G_{1}$ phase regulation, which may suggest that $\mathrm{pRB}$ and DREAM are both required to control $\mathrm{G}_{1} / \mathrm{S}$ transition. ${ }^{118}$ Consistently, triple knockout cells for the pRB-related genes cannot undergo cell cycle arrest, in contrast to $R b-/-$ single or p130-/-; p107-/- double knockout cells which still arrest. ${ }^{119}$ Genome-wide expression and protein/DNA binding studies will be instrumental in defining the distinct functions of pRB and p130/p107 - and thus DREAM. ${ }^{65}$

Another feature of the DREAM pathway may be quality of the induced cell cycle arrest. While transcriptional regulation of cell cycle proteins is slower than regulation via, for example, phosphorylation as employed by other pathways, the response to the p53-DREAM pathway may be more sustained, possibly leading to senescence as an irreversible cell cycle arrest or to induction of apoptosis. ${ }^{2,6,74}$

The function of many oncogenic factors is to stimulate cell division or, as seen from another perspective, to counteract cell cycle arrest. Consistently, p53 functions as a tumor suppressor through the p53-DREAM pathway by downregulating many oncogenic proteins such as B-Myb, FOXM1, Cyclin B1/2 and CDK1/2 (Table 1). Thus, many of the genes repressed by $\mathrm{p} 53$ are found overexpressed in tumors once the p53-DREAM pathway is impaired. Expression signatures for many cancer types comprises genes downregulation by the p53-DREAM pathway. ${ }^{120}$ In numerous studies on many cancer types, p53-DREAM targets head the list of signature genes whose aberrant expression is predictive for poor clinical outcome of cancer patients. ${ }^{121-123}$ Considering that CDK inhibitors promote repression of these genes by DREAM, functional defects of p21/CDKN1A or upstream pathway elements can be attenuated by these drugs.

In summary, the p53-p21-DREAM-E2F/CHR pathway downregulates a plethora of cell cycle genes, contributes to cell cycle arrest and is a target for cancer therapy. Researchers working on p53 function, cell cycle regulation or cancer treatment may soon join in saluting: We have a DREAM!

\section{Conflict of Interest}

The author declares no conflict of interest. 
Acknowledgements. I thank Drs Christine E Engeland and Gerd A Müller for their comments on the manuscript and for providing helpful suggestions.

1. Schwartz D, Rotter V. p53-dependent cell cycle control: response to genotoxic stress. Semin Cancer Biol 1998; 8: 325-336.

2. Vousden KH, Prives C. Blinded by the light: the growing complexity of p53. Cell 2009; 137 413-431.

3. Levine AJ, Oren M. The first 30 years of p53: growing ever more complex. Nat Rev Cancer 2009; 9: 749-758.

4. Böhlig L, Rother K. One function-multiple mechanisms: the manifold activities of $\mathrm{p} 53$ as a transcriptional repressor. J Biomed Biotechnol 2011; 2011: 464916.

5. Bunz F, Dutriaux A, Lengauer C, Waldman T, Zhou S, Brown JP et al. Requirement for p53 and p21 to sustain G2 arrest after DNA damage. Science 1998; 282: 1497-1501.

6. Vogelstein B, Lane D, Levine AJ. Surfing the p53 network. Nature 2000; 408: 307-310.

7. Jackson MW, Agarwal MK, Yang J, Bruss P, Uchiumi T, Agarwal ML et al. p130/p107/ p105Rb-dependent transcriptional repression during DNA-damage-induced cell-cycle exit at G2. J Cell Sci 2005; 118: 1821-1832.

8. Innocente SA, Abrahamson JL, Cogswell JP, Lee JM. p53 regulates a G2 checkpoin through cyclin B1. Proc Natl Acad Sci USA 1999; 96: 2147-2152.

9. Taylor WR, DePrimo SE, Agarwal A, Agarwal ML, Schonthal AH, Katula KS et al. Mechanisms of G2 arrest in response to overexpression of p53. Mol Biol Cell 1999; 10 3607-3622.

10. Krause K, Wasner M, Reinhard W, Haugwitz U, Lange-zu Dohna C, Mössner J et al. The tumour suppressor protein p53 can repress transcription of cyclin B. Nucleic Acids Res 2000; 28: 4410-4418.

11. Taylor WR, Schonthal AH, Galante J, Stark GR. p130/E2F4 binds to and represses the cdc2 promoter in response to p53. J Biol Chem 2001; 276: 1998-2006.

12. Haugwitz U, Tschöp K, Engeland K. SIRF-a novel regulator element controlling transcription from the p55Cdc/Fizzy promoter during the cell cycle. Biochem Biophys Res Commun 2004; 320: 951-960.

13. Rother K, Kirschner R, Sänger K, Böhlig L, Mössner J, Engeland K. p53 downregulates expression of the $\mathrm{G}(1) / \mathrm{S}$ cell cycle phosphatase Cdc25A. Oncogene 2007; 26: 1949-1953.

14. Haugwitz U, Wasner M, Wiedmann M, Spiesbach K, Rother K, Mössner J et al. A single cell cycle genes homology region (CHR) controls cell cycle-dependent transcription of the cdc25C phosphatase gene and is able to cooperate with E2F or Sp $1 / 3$ sites. Nucleic Acids Res 2002; 30: 1967-1976.

15. Agarwal MK, Ruhul Amin AR, Agarwal ML. DNA replication licensing factor minichromosome maintenance deficient 5 rescues p53-mediated growth arrest. Cancer Res 2007; 67: 116-121.

16. Rother K, Li YY, Tschöp K, Kirschner R, Müller GA, Mössner J et al. Expression of cyclindependent kinase subunit 1 (Cks1) is regulated during the cell cycle by a CDE/CHR tandem element and is downregulated by p53 but not by p63 or p73. Cell Cycle 2007; 6: 853-862.

17. Fischer M, Steiner L, Engeland K. The transcription factor p53: not a repressor, solely an activator. Cell Cycle 2014; 13: 3037-3058.

18. Ho J, Benchimol S. Transcriptional repression mediated by the p53 tumour suppressor. Cell Death Differ 2003; 10: 404-408

19. Fischer M, Quaas M, Nickel A, Engeland K. Indirect p53-dependent transcriptional repression of Survivin, CDC25C, and PLK1 genes requires the cyclin-dependent kinase inhibitor p21/CDKN1A and CDE/CHR promoter sites binding the DREAM complex Oncotarget 2015; 6: 41402-41417.

20. Litovchick L, Sadasivam S, Florens L, Zhu X, Swanson SK, Velmurugan S et al. Evolutionarily conserved multisubunit RBL2/p130 and E2F4 protein complex represses human cell cycle-dependent genes in quiescence. Mol Cell 2007; 26: 539-551.

21. Schmit F, Korenjak M, Mannefeld M, Schmitt K, Franke C, von Eyss B et al. LINC, a human complex that is related to $\mathrm{pRB}$-containing complexes in invertebrates regulates the expression of G2/M genes. Cell Cycle 2007; 6: 1903-1913.

22. Mannefeld M, Klassen E, Gaubatz S. B-MYB is required for recovery from the DNA damageinduced G2 checkpoint in p53 mutant cells. Cancer Res 2009; 69: 4073-4080.

23. van den Heuvel S, Dyson NJ. Conserved functions of the pRB and E2F families. Nat Rev Mol Cell Biol 2008; 9: 713-724.

24. Sadasivam S, DeCaprio JA. The DREAM complex: master coordinator of cell cycledependent gene expression. Nat Rev Cancer 2013; 13: 585-595.

25. Osterloh L, von Eyss B, Schmit F, Rein L, Hubner D, Samans B et al. The human synMuvlike protein LIN-9 is required for transcription of G2/M genes and for entry into mitosis. EMBO J 2007; 26: 144-157.

26. Sadasivam S, Duan S, DeCaprio JA. The MuvB complex sequentially recruits B-Myb and FoxM1 to promote mitotic gene expression. Genes Dev 2012; 26: 474-489.

27. Musa J, Aynaud MM, Mirabeau O, Delattre O, Grunewald TG. MYBL2 (B-Myb): a central regulator of cell proliferation, cell survival and differentiation involved in tumorigenesis. Cell Death Dis 2017; 8: e2895.

28. Schmit F, Cremer S, Gaubatz S. LIN54 is an essential core subunit of the DREAM/LINC complex that binds to the cdc2 promoter in a sequence-specific manner. FEBS J 2009; 276 5703-5716.

29. Müller GA, Quaas M, Schümann M, Krause E, Padi M, Fischer M et al. The CHR promoter element controls cell cycle-dependent gene transcription and binds the DREAM and MMB complexes. Nucleic Acids Res 2012; 40: 1561-1578.
30. Müller GA, Engeland $\mathrm{K}$. The central role of $\mathrm{CDE} / \mathrm{CHR}$ promoter elements in the regulation of cell cycle-dependent gene transcription. FEBS J 2010; 277: 877-893.

31. Müller GA, Wintsche A, Stangner K, Prohaska SJ, Stadler PF, Engeland K. The CHR site: definition and genome-wide identification of a cell cycle transcriptional element. Nucleic Acids Res 2014; 42: 10331-10350.

32. Marceau AH, Felthousen JG, Goetsch PD, Iness AN, Lee HW, Tripathi SM et al. Structural basis for LIN54 recognition of CHR elements in cell cycle-regulated promoters. Nat Commun 2016; 7: 12301.

33. Müller GA, Stangner K, Schmitt T, Wintsche A, Engeland K. Timing of transcription during the cell cycle: protein complexes binding to E2F, E2F/CLE, CDE/CHR, or CHR promoter elements define early and late cell cycle gene expression. Oncotarget 2017 (doi:10.18632/ oncotarget.10888)

34. Down CF, Millour J, Lam EW, Watson RJ. Binding of FoxM1 to G2/M gene promoters is dependent upon B-Myb. Biochim Biophys Acta 2012; 1819: 855-862.

35. Chen X, Müller GA, Quaas M, Fischer M, Han N, Stutchbury B et al. The forkhead transcription factor FOXM1 controls cell cycle-dependent gene expression through an atypical chromatin binding mechanism. Mol Cell Biol 2013; 33: 227-236.

36. Sanders DA, Gormally MV, Marsico G, Beraldi D, Tannahill D, Balasubramanian S. FOXM1 binds directly to non-consensus sequences in the human genome. Genome Biol 2015; 16: 130.

37. Zhao B, Barrera LA, Ersing I, Willox B, Schmidt SC, Greenfeld H et al. The NF-kappaB genomic landscape in lymphoblastoid B cells. Cell Rep 2014; 8: 1595-1606.

38. Paci P, Colombo T, Fiscon G, Gurtner A, Pavesi G, Farina L. SWIM: a computational tool to unveiling crucial nodes in complex biological networks. Sci Rep 2017; 7: 44797.

39. Quaas M, Müller GA, Engeland K. p53 can repress transcription of cell cycle genes through a 21 (WAF1/CIP1)-dependent switch from MMB to DREAM protein complex binding at CHR promoter elements. Cell Cycle 2012; 11: 4661-4672.

40. el-Deiry WS, Tokino T, Velculescu VE, Levy DB, Parsons R, Trent JM et al. WAF1, a potential mediator of p53 tumor suppression. Cell 1993; 75: 817-825.

41. Abbas T, Dutta A. p21 in cancer: intricate networks and multiple activities. Nat Rev Cancer 2009; 9: 400-414.

42. Melino G. p63 is a suppressor of tumorigenesis and metastasis interacting with mutant $p 53$. Cell Death Differ 2011; 18: 1487-1499.

43. Marcel V, Dichtel-Danjoy ML, Sagne C, Hafsi H, Ma D, Ortiz-Cuaran S et al. Biological functions of p53 isoforms through evolution: lessons from animal and cellular models. Cell Death Differ 2011; 18: 1815-1824.

44. el-Deiry WS, Kern SE, Pietenpol JA, Kinzler KW, Vogelstein B. Definition of a consensus binding site for p53. Nat Genet 1992; 1: 45-49.

45. Yang A, Zhu Z, Kettenbach A, Kapranov P, McKeon F, Gingeras TR et al. Genome-wide mapping indicates that p73 and p63 co-occupy target sites and have similar dna-binding profiles in vivo. PLOS ONE 2010; 5: e11572.

46. Marshall CB, Mays DJ, Beeler JS, Rosenbluth JM, Boyd KL, Santos Guasch GL et al. p73 is required for multiciliogenesis and regulates the Foxj1-associated gene network. Cell Rep 2016; 14: 2289-2300.

47. Pellacani D, Bilenky M, Kannan N, Heravi-Moussavi A, Knapp DJ, Gakkhar S et al. Analysis of normal human mammary epigenomes reveals cell-specific active enhancer states and associated transcription factor networks. Cell Rep 2016; 17: 2060-2074.

48. Dietz S, Rother K, Bamberger C, Schmale H, Mössner J, Engeland K. Differential regulation of transcription and induction of programmed cell death by human p53-family members p63 and p73. FEBS Lett 2002; 525: 93-99.

49. Candi E, Agostini M, Melino G, Bernassola F. How the TP53 family proteins TP63 and TP73 contribute to tumorigenesis: regulators and effectors. Hum Mutat 2014; 35 : 702-714.

50. Rother K, Dengl M, Lorenz J, Tschöp K, Kirschner R, Mössner J et al. Gene expression of cyclin-dependent kinase subunit Cks2 is repressed by the tumor suppressor p53 but not by the related proteins p63 or p73. FEBS Lett 2007; 581: 1166-1172.

51. Sohr S, Engeland K. RHAMM is differentially expressed in the cell cycle and downregulated by the tumor suppressor p53. Cell Cycle 2008; 7: 3448-3460.

52. Gebel J, Luh LM, Coutandin D, Osterburg C, Lohr F, Schafer B et al. Mechanism of TAp73 inhibition by DeltaNp63 and structural basis of p63/p73 hetero-tetramerization. Cell Death Differ 2016; 23: 1930-1940

53. Billant O, Leon A, Le GS, Friocourt G, Blondel M, Voisset C. The dominant-negative interplay between p53, p63 and p73: A family affair. Oncotarget 2016; 7: 69549-69564.

54. Harper JW, Elledge SJ, Keyomarsi K, Dynlacht B, Tsai LH, Zhang P et al. Inhibition of cyclin-dependent kinases by p21. Mol Biol Cell 1995; 6: 387-400.

55. Dulic V, Kaufmann WK, Wilson SJ, Tlsty TD, Lees E, Harper JW et al. p53-dependent inhibition of cyclin-dependent kinase activities in human fibroblasts during radiationinduced G1 arrest. Cell 1994; 76: 1013-1023.

56. Farkas T, Hansen K, Holm K, Lukas J, Bartek J. Distinct phosphorylation events regulate p130- and p107-mediated repression of E2F-4. J Biol Chem 2002; 277: 26741-26752.

57. Dyson NJ. RB1: a prototype tumor suppressor and an enigma. Genes Dev 2016; 30: 1492-1502.

58. Sherr CJ, Roberts JM. CDK inhibitors: positive and negative regulators of G1-phase progression. Genes Dev 1999; 13: 1501-1512.

59. Shiohara M, el-Deiry WS, Wada M, Nakamaki T, Takeuchi S, Yang R et al. Absence of WAF1 mutations in a variety of human malignancies. Blood 1994; 84: 3781-3784. 
60. Deng C, Zhang P, Harper JW, Elledge SJ, Leder P. Mice lacking P21CIP1/WAF1 undergo normal development, but are defective in G1 checkpoint control. Cell 1995; 82: 675-684.

61. Valente LJ, Grabow S, Vandenberg CJ, Strasser A, Janic A. Combined loss of PUMA and p21 accelerates c-MYC-driven lymphoma development considerably less than loss of one allele of p53. Oncogene 2016; 35: 3866-3871.

62. Valente LJ, Aubrey BJ, Herold MJ, Kelly GL, Happo L, Scott CL et al. Therapeutic response to non-genotoxic activation of p53 by Nutlin3a is driven by PUMA-mediated apoptosis in lymphoma cells. Cell Rep 2016; 14: 1858-1866.

63. Cheng M, Olivier P, Diehl JA, Fero M, Roussel MF, Roberts JM et al. The p21(Cip1) and p27(Kip1) CDK 'inhibitors' are essential activators of cyclin D-dependent kinases in murine fibroblasts. EMBO J 1999; 18: 1571-1583.

64. Cerqueira A, Martin A, Symonds CE, Odajima J, Dubus P, Barbacid M et al. Genetic characterization of the role of the Cip/Kip family of proteins as cyclin-dependent kinase inhibitors and assembly factors. Mol Cell Biol 2014; 34: 1452-1459.

65. Fischer M, Grossmann P, Padi M, DeCaprio JA. Integration of TP53, DREAM, MMBFOXM1 and RB-E2F target gene analyses identifies cell cycle gene regulatory networks. Nucleic Acids Res 2016; 44: 6070-6086.

66. Fischer M, Quaas M, Steiner L, Engeland K. The p53-p21-DREAM-CDE/CHR pathway regulates G2/M cell cycle genes. Nucleic Acids Res 2016; 44: 164-174.

67. Fischer M. Census and evaluation of p53 target genes. Oncogene 2017; 36 3943-3956.

68. Fischer M, Grundke I, Sohr S, Quaas M, Hoffmann S, Knörck A et al. p53 and cell cycle dependent transcription of kinesin family member 23 (KIF23) is controlled via a CHR promoter element bound by DREAM and MMB complexes. PLoS One 2013; 8: e63187.

69. Fischer M, Quaas M, Wintsche A, Müller GA, Engeland K. Polo-like kinase 4 transcription is activated via CRE and NRF1 elements, repressed by DREAM through CDE/CHR sites and deregulated by HPV E7 protein. Nucleic Acids Res 2014; 42: 163-180.

70. de Toledo SM, Azzam El, Keng P, Laffrenier S, Little JB. Regulation by ionizing radiation of CDC2, cyclin A, cyclin B, thymidine kinase, topoisomerase llalpha, and RAD51 expression in normal human diploid fibroblasts is dependent on p53/p21Waf1. Cell Growth Differ 1998; 9. $887-896$

71. Gottifredi V, Karni-Schmidt O, Shieh SS, Prives C. p53 down-regulates CHK1 through p21 and the retinoblastoma protein. Mol Cell Biol 2001; 21: 1066-1076.

72. Spurgers KB, Gold DL, Coombes KR, Bohnenstiehl NL, Mullins B, Meyn RE et al. Identification of cell cycle regulatory genes as principal targets of p53-mediated transcriptional repression. J Biol Chem 2006; 281: 25134-25142.

73. Vaziri C, Saxena S, Jeon Y, Lee C, Murata K, Machida Y et al. A p53-dependent checkpoint pathway prevents rereplication. Mol Cell 2003; 11: 997-1008.

74. Bartek J, Lukas J. Pathways governing G1/S transition and their response to DNA damage. FEBS Lett 2001; 490: 117-122.

75. Prioleau MN, MacAlpine DM. DNA replication origins-where do we begin? Genes Dev 2016; 30: 1683-1697.

76. Yan Z, DeGregori J, Shohet R, Leone G, Stillman B, Nevins JR et al. Cdc6 is regulated by E2F and is essential for DNA replication in mammalian cells. Proc Natl Acad Sci USA 1998; 95: 3603-3608.

77. Dou QP, Zhao S, Levin AH, Wang J, Helin K, Pardee AB. G1/S-regulated E2F-containing protein complexes bind to the mouse thymidine kinase gene promoter. J Biol Chem 1994; 269: 1306-1313.

78. Blake MC, Azizkhan JC. Transcription factor E2F is required for efficient expression of the hamster dihydrofolate reductase gene in vitro and in vivo. Mol Cell Biol 1989; 9: 4994-5002.

79. Taylor WR, Stark GR. Regulation of the G2/M transition by p53. Oncogene 2001; 20: 1803-1815.

80. Krause K, Haugwitz U, Wasner M, Wiedmann M, Mössner J, Engeland K. Expression of the cell cycle phosphatase cdc $25 \mathrm{C}$ is down-regulated by the tumour suppressor protein $\mathrm{p} 53$ but not by p73. Biochem Biophys Res Commun 2001; 284: 743-750.

81. Wasner M, Tschöp K, Spiesbach K, Haugwitz U, Johne C, Mössner J et al. Cyclin B1 transcription is enhanced by the p300 coactivator and regulated during the cell cycle by a CHR-dependent repression mechanism. FEBS Lett 2003; 536: 66-70.

82. Cross RA, McAinsh A. Prime movers: the mechanochemistry of mitotic kinesins. Nat Rev Mol Cell Biol 2014; 15: 257-271.

83. Iltzsche F, Simon K, Stopp S, Pattschull G, Francke S, Wolter P et al. An important role for Myb-MuvB and its target gene KIF23 in a mouse model of lung adenocarcinoma. Oncogene 2017; 36: 110-121.

84. Musacchio A, Salmon ED. The spindle-assembly checkpoint in space and time. Nat Rev Mol Cell Biol 2007; 8: 379-393.

85. Rao CV, Yamada HY, Yao Y, Dai W. Enhanced genomic instabilities caused by deregulated microtubule dynamics and chromosome segregation: a perspective from genetic studies in mice. Carcinogenesis 2009; 30: 1469-1474.

86. Nam HJ, Naylor RM, van Deursen JM. Centrosome dynamics as a source of chromosomal instability. Trends Cell Biol 2015; 25: 65-73.

87. Funk LC, Zasadil LM, Weaver BA. Living in CIN: mitotic infidelity and its consequences for tumor promotion and suppression. Dev Cell 2016; 39: 638-652.

88. Nath S, Ghatak D, Das P, Roychoudhury S. Transcriptional control of mitosis: deregulation and cancer. Front Endocrinol (Lausanne) 2015; 6: 60.
89. Vitale I, Galluzzi L, Castedo M, Kroemer G. Mitotic catastrophe: a mechanism for avoiding genomic instability. Nat Rev Mol Cell Biol 2011; 12: 385-392.

90. Thompson SL, Compton DA. Proliferation of aneuploid human cells is limited by a p53dependent mechanism. J Cell Biol 2010; 188: 369-381.

91. Wolter P, Hanselmann S, Pattschull G, Schruf E, Gaubatz S. Central spindle proteins and mitotic kinesins are direct transcriptional targets of MuvB, B-MYB and FOXM1 in breast cancer cell lines and are potential targets for therapy. Oncotarget 2017; 8 : 11160-11172.

92. Wolter $\mathrm{P}$, Schmitt K, Fackler M, Kremling H, Probst L, Hauser S et al. GAS2L3, a target gene of the DREAM complex, is required for proper cytokinesis and genomic stability. J Cell Sci 2012; 125: 2393-2406.

93. Li C, Lin M, Liu J. Identification of PRC1 as the $\mathrm{p} 53$ target gene uncovers a novel function of p53 in the regulation of cytokinesis. Oncogene 2004; 23: 9336-9347.

94. Muller S, Almouzni G. Chromatin dynamics during the cell cycle at centromeres. Nat Rev Genet 2017; 18: 192-208

95. Filipescu D, Naughtin M, Podsypanina K, Lejour V, Wilson L, Gurard-Levin ZA et al. Essential role for centromeric factors following p53 loss and oncogenic transformation. Genes Dev 2017; 31: 463-480.

96. Fava LL, Schuler F, Sladky V, Haschka MD, Soratroi C, Eiterer L et al. The PIDDosome activates p53 in response to supernumerary centrosomes. Genes Dev 2017; 31: 34-45.

97. Fukasawa K, Choi T, Kuriyama R, Rulong S, Vande Woude GF. Abnormal centrosome amplification in the absence of p53. Science 1996; 271: 1744-1747.

98. Levine MS, Bakker B, Boeckx B, Moyett J, Lu J, Vitre B et al. Centrosome amplification is sufficient to promote spontaneous tumorigenesis in mammals. Dev Cell 2017; 40: 313-322.

99. Wang AT, Smogorzewska A. SnapShot: Fanconi anemia and associated proteins. Cell 2015; 160: 354.

100. Ceccaldi R, Sarangi P, D'Andrea AD. The Fanconi anaemia pathway: new players and new functions. Nat Rev Mol Cell Biol 2016; 17: 337-349.

101. Jaber S, Toufektchan E, Lejour V, Bardot B, Toledo F. p53 downregulates the Fancon anaemia DNA repair pathway. Nat Commun 2016; 7: 11091.

102. Hupp TR, Meek DW, Midgley CA, Lane DP. Regulation of the specific Dna-binding function of P53. Cell 1992; 71: 875-886.

103. Greider CW. Regulating telomere length from the inside out: the replication fork model. Genes Dev 2016; 30: 1483-1491.

104. Hoffmann S, Smedegaard S, Nakamura K, Mortuza GB, Raschle M, Ibanez de OA et al. TRAIP is a PCNA-binding ubiquitin ligase that protects genome stability after replication stress. J Cell Biol 2016; 212: 63-75.

105. Michl J, Zimmer J, Tarsounas M. Interplay between Fanconi anemia and homologous recombination pathways in genome integrity. EMBO J 2016; 35: 909-923.

106. Bindra RS, Gibson SL, Meng A, Westermark U, Jasin M, Pierce AJ et al. Hypoxiainduced down-regulation of BRCA1 expression by E2Fs. Cancer Res 2005; 65 : $11597-11604$

107. Valenti F, Ganci F, Fontemaggi G, Sacconi A, Strano S, Blandino $G$ et al. Gain of function mutant p53 proteins cooperate with E2F4 to transcriptionally downregulate RAD17 and BRCA1 gene expression. Oncotarget 2015; 6: 5547-5566.

108. O'Leary B, Finn RS, Turner NC. Treating cancer with selective CDK4/6 inhibitors. Nat Rev Clin Oncol 2016; 13: 417-430.

109. Beijersbergen RL, Carlee L, Kerkhoven RM, Bernards R. Regulation of the retinoblastoma protein-related p107 by G1 cyclin complexes. Genes Dev 1995; 9: 1340-1353.

110. Bruce JL, Hurford RK Jr., Classon M, Koh J, Dyson N. Requirements for cell cycle arrest by p16INK4a. Mol Cell 2000; 6: 737-742.

111. Dyson N, Howley PM, Munger K, Harlow E. The human papilloma virus-16 E7 oncoprotein is able to bind to the retinoblastoma gene product. Science 1989; 243: 934-937.

112. Nor Rashid N, Yusof R, Watson RJ. Disruption of repressive p130-DREAM complexes by human papillomavirus $16 \mathrm{E} 6 / \mathrm{E} 7$ oncoproteins is required for cell-cycle progression in cervical cancer cells. J Gen Virol 2011; 92: 2620-2627.

113. Scheffner M, Werness BA, Huibregtse JM, Levine AJ, Howley PM. The E6 oncoprotein encoded by human papillomavirus types 16 and 18 promotes the degradation of p53. Cell 1990; 63: 1129-1136.

114. Rozenblatt-Rosen O, Deo RC, Padi M, Adelmant G, Calderwood MA, Rolland T et al. Interpreting cancer genomes using systematic host network perturbations by tumour virus proteins. Nature 2012; 487: 491-495.

115. Zhou Y, Zhang Q, Gao G, Zhang X, Liu Y, Yuan S et al. Role of WDHD1 in human papillomavirus-mediated oncogenesis identified by transcriptional profiling of E7expressing cells. J Virol 2016; 90: 6071-6084.

116. Fischer M, Uxa S, Stanko C, Magin TM, Engeland K. Human papilloma virus E7 oncoprotein abrogates the p53-p21-DREAM pathway. Sci Rep 2017; 7: 2603

117. Tovy A, Spiro A, McCarthy R, Shipony Z, Aylon Y, Allton K et al. p53 is essential for DNA methylation homeostasis in naive embryonic stem cells, and its loss promotes clonal heterogeneity. Genes Dev 2017; 31: 959-972.

118. Brugarolas J, Bronson RT, Jacks T. p21 is a critical CDK2 regulator essential for proliferation control in Rb-deficient cells. J Cell Biol 1998; 141: 503-514.

119. Sage J, Mulligan GJ, Attardi LD, Miller A, Chen S, Williams B et al. Targeted disruption of the three Rb-related genes leads to loss of $\mathrm{G}(1)$ control and immortalization. Genes Dev 2000; 14: 3037-3050. 
120. Cheng WY, Ou Yang TH, Anastassiou D. Biomolecular events in cancer revealed by attractor metagenes. PLoS Comput Biol 2013; 9: e1002920.

121. van 't Veer LJ, Dai H, van de Vijver MJ, He YD, Hart AA, Mao M et al. Gene expression profiling predicts clinical outcome of breast cancer. Nature 2002; 415: 530-536.

122. Carter SL, Eklund AC, Kohane IS, Harris LN, Szallasi Z. A signature of chromosomal instability inferred from gene expression profiles predicts clinical outcome in multiple human cancers. Nat Genet 2006; 38: 1043-1048.

123. Chibon F, Lagarde P, Salas S, Perot G, Brouste V, Tirode F et al. Validated prediction of clinical outcome in sarcomas and multiple types of cancer on the basis of a gene expression signature related to genome complexity. Nat Med 2010; 16 : 781-787.

124. Holohan B, Wright WE, Shay JW. Cell biology of disease: telomeropathies: an emerging spectrum disorder. J Cell Biol 2014; 205: 289-299. (c) (i) (2) (2) This work is licensed under a Creative Commons Attribution-NonCommercial-ShareAlike 4.0 International License. The images or other third party material in this article are included in the article's Creative Commons license, unless indicated otherwise in the credit line; if the material is not included under the Creative Commons license, users will need to obtain permission from the license holder to reproduce the material. To view a copy of this license, visit http://creativecommons.org/licenses/by-nc-sa/4.0/

(C) The Author(s) 2018 